\title{
The role of Src-homology 2 domain-containing tyrosine phosphatase 2 in signaling and tumorigenesis of basal type/triple negative breast cancer
}

\author{
Fatimah Kh. Matalkah \\ West Virginia University
}

Follow this and additional works at: https://researchrepository.wvu.edu/etd

\author{
Recommended Citation \\ Matalkah, Fatimah Kh., "The role of Src-homology 2 domain-containing tyrosine phosphatase 2 in \\ signaling and tumorigenesis of basal type/triple negative breast cancer" (2012). Graduate Theses, \\ Dissertations, and Problem Reports. 4894. \\ https://researchrepository.wvu.edu/etd/4894
}

This Thesis is protected by copyright and/or related rights. It has been brought to you by the The Research Repository @WVU with permission from the rights-holder(s). You are free to use this Thesis in any way that is permitted by the copyright and related rights legislation that applies to your use. For other uses you must obtain permission from the rights-holder(s) directly, unless additional rights are indicated by a Creative Commons license in the record and/ or on the work itself. This Thesis has been accepted for inclusion in WVU Graduate Theses, Dissertations, and Problem Reports collection by an authorized administrator of The Research Repository @ WVU. For more information, please contact researchrepository@mail.wvu.edu. 


\section{The role of Src-homology 2 domain-containing tyrosine phosphatase 2 in signaling and tumorigenesis of basal type/triple negative breast cancer}

Fatimah Kh. Matalkah

Thesis submitted to the School of Medicine at West Virginia University in partial fulfillment of the requirements for the degree of

Master of Science

in

Biomedical Sciences

Michael Schaller, Ph.D., Chair

Yehenew Agazie, Ph.D.

Scott Weed, Ph.D.

Karen Martin, Ph.D.

Department of Biomedical Sciences

Morgantown, West Virginia

2012

Key words: SHP2, Basal Type and Triple Negative Breast Cancer, Biomedical Sciences Copyright of 2012, Fatimah Kh. Matalkah 


\begin{abstract}
The role of Src-homology 2 domain-containing tyrosine phosphatase 2 in signaling and tumorigenesis of basal type/triple negative breast cancer
\end{abstract}

\begin{abstract}
Fatimah Matalkah
Basal type/triple negative breast cancer (BTBC) represents a distinct tumor group that is characterized by an aggressive disease phenotype and poor clinical outcome. Patients with this subtype cannot benefit from the available anti-hormone and anti-HER2 targeted therapies (e.g. tamoxifen and herceptin). Therefore, characterizing potential therapeutic targets is urgently needed. We reasoned that the Src-homology 2 domain-containing tyrosine phosphatase 2 (SHP2) could serve as a therapeutic target in BTBC, because of its critical regulation of epidermal growth factor recptor (EGFR) which is overexpressed in BTBC. Here, we demonstrated that SHP2 knockdown in BTBC cell lines suppressed cell proliferation, migration, and transformation. Furthermore, inhibition of SHP2 decreased the level of MMP9 in the conditioned media as shown by zymography and affected the invasive phenotype of BTBC cell lines in 3D matrigel. Most importantly, the results obtained from xenografts confirm that SHP2 plays an important role in the maintenance and progression of BTBC development and lung metastasis. Mechanistically, SHP2 depletion resulted in less-sustained EGF-induced Ras activation and decreased $\beta$-catenin level, the latter of which resulted in an increase in p27 level. Taken together, these observations suggest that SHP2 plays essential roles in the development of BTBC and provide a rationale for targeting SHP2 in BTBC.
\end{abstract}




\section{ACKNOWLEDGEMENTS}

I would like to express my gratitude to my advisor Dr. Yehenew Agazie for giving me the opportunity to work in his lab and for the financial support he provided for this work. His suggestions and useful comments were invaluable to the completion of my thesis.

It is with immense gratitude that I acknowledge the wisdom, the continued support, and the guidance of my committee members Drs. Michael Schaller, Scott Weed, and Karen Martin. I'm also in debt to Prof. Fred Minnear, for all the valuable help, advice, and suggestions.

I owe a lot to my colleagues in the cancer cell biology program and the biochemistry department, with special thanks to Zach Hartman for providing help with the wound healing assay and for the fruitful discussions about lab work. I must also acknowledge the many fellow students, staff, and faculty, too many to mention, for their help and support.

Finally, very special thanks to my husband, and to my family for supporting me all the way, and to my kids Malik and Razan for making life worthwhile. 


\section{Table of Contents}

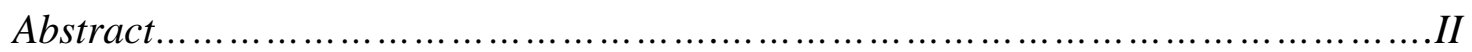

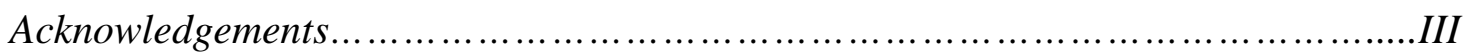

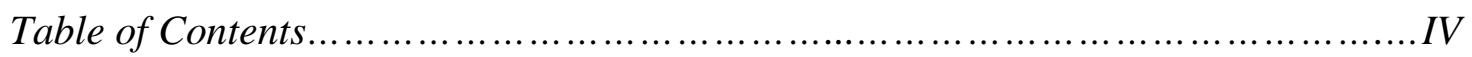

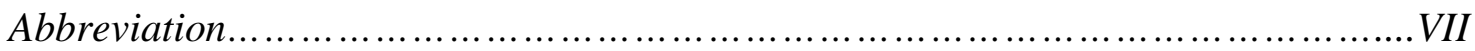

1. INTRODUCTION AND LITERATURE REVIEW .....................................1

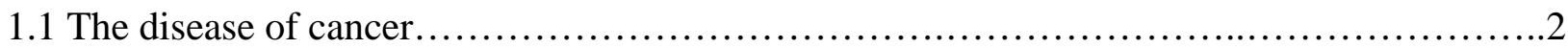

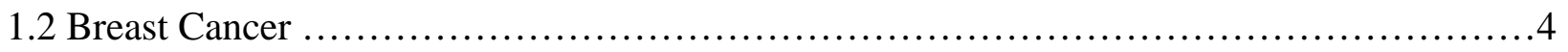

1.2.1 Epidemiology and pathophysiology of breast cancer...................................

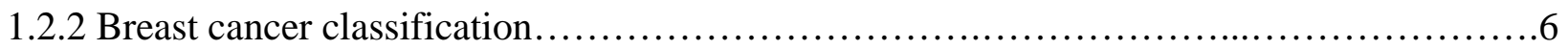

1.2.3 Basal-like breast cancer subtype.................................................

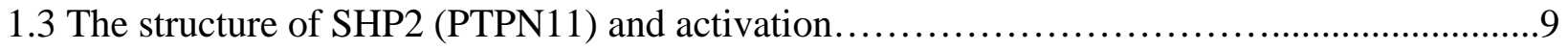

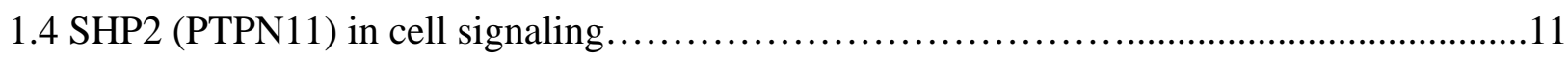

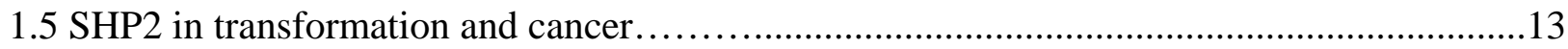

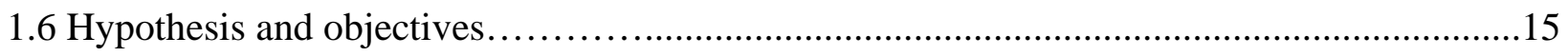

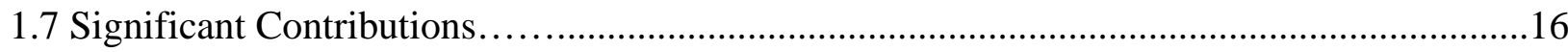

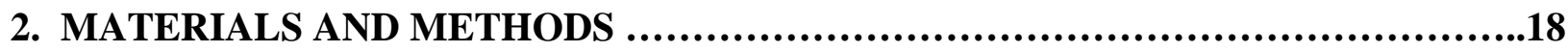

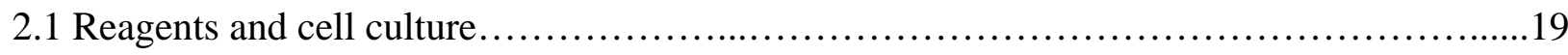

2.2 Preparation of cell and tissue lysates....................................................... 
2.3 Polyacrylamide gel electrophoresis (PAGE) and immunblotting analysis................. 20

2.4 Short hairpin ribonucleic acid (shRNA) construction and stable cell lines production...................................................................20

2.5 Cell proliferation assay.............................................................

2.6 Monolayer-wound healing assay ..............................................22

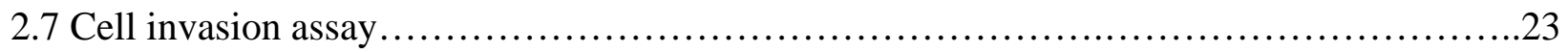

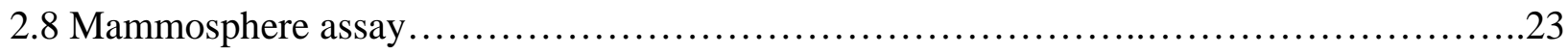

2.9 Anchorage-independent growth assay..........................................24

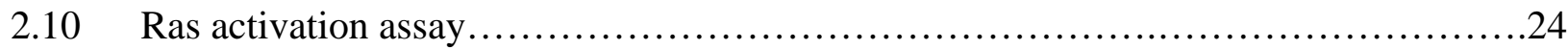

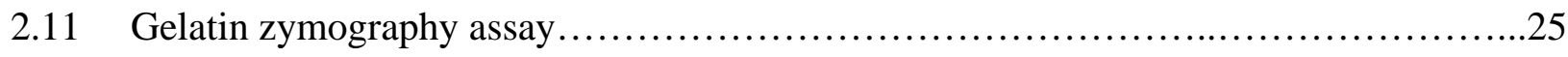

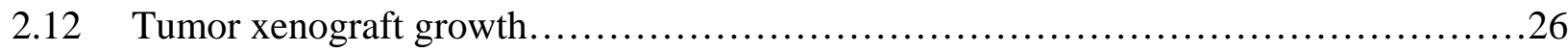

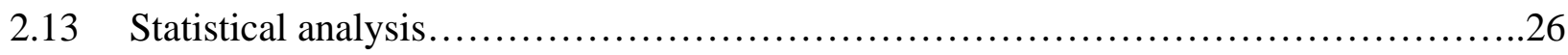

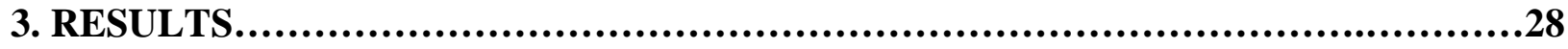

3.1 shRNA-mediated silencing of SHP2 expression....................................29

3.2 SHP2 Promotes BTBC cells proliferation.......................................

3.3 SHP2 depletion suppresses anchorage-independent phenotype in BTBC cells.............33

3.4 SHP2 is required for the migration of BTBC cells..................................

3.5 The invasive property of BTBC cell is SHP2 dependent.................................37

3.6 Loss of SHP2 decreases the level of matrix metalloproteinase 9 (MMP9) in conditioned

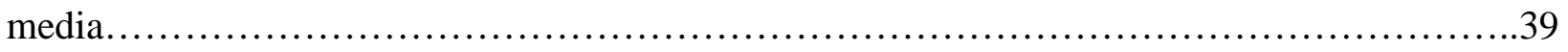

3.7 Depletion of SHP2 suppresses tumorigenesis in BTBC cells ...........................41

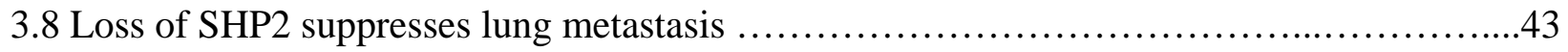

3.9 SHP2 depletion decreases self-renewal capacity of tumor initiating cells (TICs)............44 


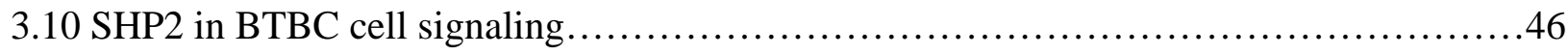

3.10.1 SHP2 is important for EGF-induced Ras activation .................................46

3.10.2 SHP2 modulates $\beta$-catenin and downstream signaling............................ 48

4. DISCUSION................................................................................

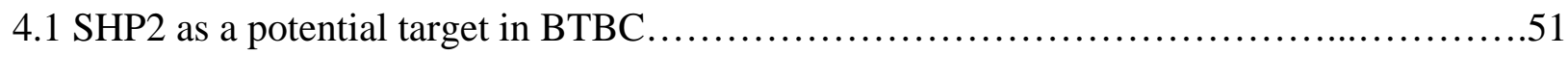

4.2 SHP2 knockdown results in decreased cell proliferation................................51

4.3 Inhibition of SHP2 suppresses cell transformation....................................52

4.4 Depletion of SHP2 suppresses BTBC wound healing In Vitro.............................53

4.5 SHP2 knockdown results in decreased cell invasion.................................53

4.6 SHP2 depletion decreased MMP9 level in conditioned media...............................54

4.7 SHP2 knockdown suppresses xenograft tumor grwoth and lung metastasis..................55

4.8 Inhibition of SHP2 suppresses the self-renewal capacity of TICs.........................56

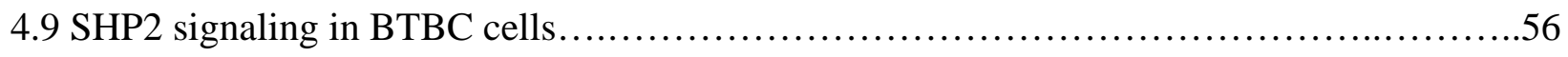

4.9.1 SHP2 regulates EGF-induced Ras activation in BTBC cells............................56

4.9.2 SHP2 regulates the $\mathrm{Wnt} / \mathrm{\beta}$-catenin signaling in BTBC cells...........................57

4.10 Study limitations and future directions ......................................................

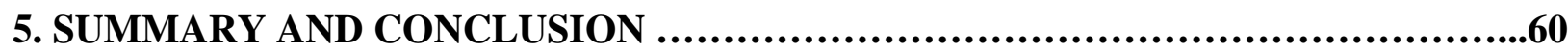

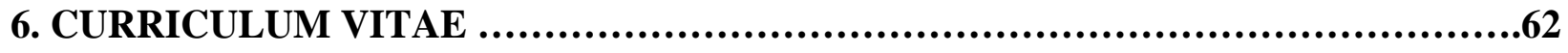

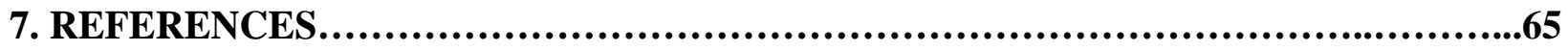




$\begin{array}{ll}\text { Abbreviations } \\ \text { BTBC } & \text { Basal Type Triple Negative Breast Cancer } \\ \text { SHP2 } & \text { Src-homology } 2 \text { domain-containing tyrosine phosphatase 2 } \\ \text { TIC } & \text { Tumor Initiating Cells } \\ \text { HER2 } & \text { Epidermal growth factor receptor } 2 \\ \text { EGFR } & \text { Epidermal growth factor receptor } \\ \text { ER } & \text { Estrogen receptor } \\ \text { PR } & \text { Progestrone receptor } \\ \text { PI3K } & \text { phosphatidylinositol-3-kinase } \\ \text { MAPK } & \text { Mitogen activated protein kinase } \\ \text { ERK } & \text { Extracellular signal-regulated kinase } \\ \text { JMML } & \text { juvenile myelomonocytic leukemia } \\ \text { EGF } & \text { Epidermal growth factor }\end{array}$


1. INTRODUCTION AND LITERATURE REVIEW 


\subsection{The disease of cancer}

Cancer is a complex multigenic disease, encompassing more than 100 entities arising from different types of cells and organs of the human body [1]. Each tumor type has unique somatic and epigenetic alterations [2]. The major known somatic alterations are mutations, chromosomal re-arrangement, copy number gains or losses, and integration of nucleic acid of foreign origin (e.g viral genome) [3]. On the other hand, the epigenetic alterations include changes in DNA methylation, histone modification, and non-coding RNA mediating silencing of protein expression [4]. It is just this complexity that is believed to hamper the development of a universally effective therapy for all different types of cancer.

The causes of cancer are many and varied including genetic and environmental factors, as well as infectious agents [1]. Moreover, around $30 \%$ of cancer deaths in the world are related to lifestyle and personal behaviors, which include tobacco smoking, alcohol consumption, and diets low in fruits and vegetables. Collectively, these factors can transform a normal cell into a malignant cell by driving specific series of genetic and epigenetic changes in proto-oncogenes, tumor suppressor genes, and other genes that control normal cell function [5]. Mutations affecting proto-oncogenes are typically activating in nature providing the transformed cell with new properties. These include sustained cell growth and proliferation, protection from programmed cell death, and the ability to adapt to different tissue microenvironments. However, mutations affecting tumor suppressor genes in cancer cells are loss of function mutations. Generally, the loss of function in tumor suppressor genes results in loss of accurate DNA replication, inability to control cell cycle, and loss of cell polarity [6]. Overall, these mutations affecting tumor suppressor genes and proto-oncogenes result in tumor development and metastasis. In general, a cell that has acquired a cancerous state exhibits the following 
properties: self-sufficiency in growth signals, insensitivity to growth inhibitory signals, evasion of apoptosis signals, sustaining proliferation and angiogenesis, tissue invasion, and metastasis [6].

Cancer is a major public health problem around the world resulting in $13 \%$ of all human death. According to the World Health Organization, 7.6 million people died from cancer during 2008. In the United States cancer is responsible for about $25 \%$ of all deaths, making it the second leading cause of death after heart disease. In 2012 nearly one and a half million are expected to be diagnosed with cancer, and about half a million Americans will die of cancer [7]. As of 2011, the most prevalent type of cancer amongst males in the United States is prostate cancer, whereas in females it is breast cancer. However, the leading cause of death in both males and females is lung cancer, which contributes approximately $30 \%$ of all deaths due to cancer [8].

Cancer treatment costs billions of dollars, causing a financial burden for victims of cancer and society as a whole. In 2007 the National Institute of Health estimated the cost of cancer at 226.8 billion dollars due to both medical expenses and lost productivity [8]. Moreover, according to the World Health Organization, death from cancer worldwide is expected to keep rising with an estimated 13.1 million deaths in 2030.

In conclusion, cancer represents a huge burden to the economy and to public health worldwide. Ongoing research is needed to decrease suffering and death due to cancer. Identifying the genetic and protein changes in cancer cells would provide prognostic markers and molecular targets for therapeutic intervention [9]. 


\subsection{Breast Cancer}

\subsubsection{Epidemiology and pathophysiology of breast cancer}

Breast cancer is a type of cancer that affects the breast tissues. And like any other type of cancer the exact causes are unknown, but both environmental and genetic factors are involved. Breast cancer can strike both males and females; however, women are much more likely to develop the disease than men [10]. Worldwide, breast cancer is the second leading cause of cancer-related death in women, with almost 1.4 million diagnoses and approximately 500,000 deaths in 2008 [11]. In the United States, breast cancer is the most common form of cancer among women after skin cancer, with over 200,000 diagnoses and nearly 40,000 deaths in 2011, ranking as the second leading cause of cancer-related deaths in women after lung cancer [7].

Breast cancer is a malignant tumor that grows in one or both of the breasts, and usually develops in the ducts and the lobules, the milk-producing area of the breast. There are different types of breast cancer that can be grouped based on their tissue penetrance into two main categories-noninvasive and invasive. The non-invasive type can be further divided into two types: ductal carcinoma in situ (DCIS) and lobular carcinoma in situ (LCIS). As their name suggests, DCIS and LCIS are confined to the ducts and lobules of the breast, respectively, and they don't invade the surrounding tissue. The invasive breast tumors can also be divided into two types: infiltrating ductal carcinoma and infiltrating lobular carcinoma. Invasive carcinoma types are more serious than the noninvasive tumor types, and as their name suggest these tumors invade the wall of the ducts and lobules, respectively, and infiltrate outside of it, spreading to different parts of the body such as the lung, bone, liver and brain. The most common type of breast cancer is infiltrating ductal carcinoma, accounting for $70-80 \%$ of all the cases. More 
often, mortality from breast cancer is due to metastasis, in which tumor cells spread to distant sites and form secondary tumors that interfere with the function of vital organs.

Treatment options that are available for patients with breast cancer include surgery, radiotherapy, chemotherapy, and anti-hormonal/anti-HER2 targeted therapies. There are two surgical options available for patients with breast cancer; lumpectomy, where only the tumor tissue is removed, and mastectomy in which the whole breast is removed. The surgical option is often accompanied by other treatment options such as radiotherapy or chemotherapy. On the other hand, the anti-hormonal and anti-HER2 targeted therapies are only applicable to patients with the hormonal receptors-positive $(\mathrm{ER} / \mathrm{PR}+)$ and epidermal growth factor 2 (HER2)overexpressing tumors, respectively. Diagnosis with hormone-positive tumors is considered good prognosis for patients since these tumors are less aggressive and respond well to targeted therapies (e.g., Tamoxifen). Although targeted therapy is available to HER2-overexpressing tumors, these tumors are characterized with aggressive growth and development of resistance. Furthermore, the emergence of therapy-resistant cancer cells is one of the unavoidable consequences of targeted therapy [12]. As a result, significant numbers of patients do not show a response to treatment or experience relapse and disease progression from which they will succumb [10].

Despite significant improvements in breast cancer treatment strategies, current therapies are limited by the emergence of therapy-resistant cancer cells and the disease remains the most deadly cancer in women worldwide [12]. Understanding the underlying resistance mechanisms and identifying new therapeutic targets has been one of the most intense areas of breast cancer research $[10,13]$. 


\subsubsection{Breast cancer classification}

Breast cancer is a heterogeneous disease in terms of histology, gene expression, and response to therapy. Two taxonomy systems have been proposed and used in an attempt to clarify such heterogeneity. The clinical system, which relies on immunohistochemistry to identify the

presence of several receptors, namely estrogen (ER), progesterone (PR), and epidermal growth factor 2 (HER2) classifies breast cancer into three subtypes [14, 15]. These are ER/PR positive, HER2-overexpressing, and triple negative tumors. The more recent system, pioneered by Perou and colleagues, allows the subtypes to be assessed based on gene expression by the microarray technique [14, 16-19]. Such classification defines five distinct subtypes of breast cancer. These include luminal A, luminal B, HER2-overexpressing, basal-like, and normal breast-like [16, 17]. A recently-added subtype is the claudin low that is believed to be enriched for cells with stemlike markers, which have an elevated ability to proliferate and form new tumors [18]. The luminal (A and B) are ER-positive groups that express genes normally found in the luminal cells lining the inner layer of breast ducts, therefore, they are termed the "luminal group" [14]. On the other hand, HER2-overexpressing tumors are characterized by overexpression of HER2 receptor and the genes associated with the HER2 pathway. The normal breast-like subtype is poorly characterized with the notion that this subtype is an artifact of the expression profiling. Therefore, the clinical significance of this subtype is yet to be determined. Of particular concern is the basal-like subtype, which accounts for up to $10-20 \%$ of all breast cancer cases, but is responsible for a disproportionately higher number of deaths $[14,15,18,19]$. The major factors are the highly metastatic nature of the disease and the absence of targeted therapy. 


\subsubsection{Basal-like breast cancer subtype}

Basal-like tumors represent $10-20 \%$ of all breast carcinomas, and are so named because they express genes normally found in basal/myoepithelial cells of the breast including high molecular weigh cytokeratins CK5 and CK17. Clinically, they affect younger patients, are more prevalent in African-American women and are associated with unfavorable outcome. Histologically, the basal-like tumors are characterized by high histological grade, and high mitotic indices [15]. They commonly lack expression of estrogen receptor, progesterone receptor as well as HER2 receptor; a feature referred to as triple negative $[15,19]$. The triple negative phenotype itself defines an aggressive disease that lack the benefit of targeted therapy available for the other subtypes, specifically the hormonal therapy targeting the ER/PR-expressing tumors, and trastuzumab targeting the HER2-overexpersssing breast tumors. Interestingly, there exists more than $85 \%$ overlap between the basal-like and triple negative tumors in gene expression profile [20]. This overlap has led to the interchangeable use of these terms by many investigators and to the acceptance of triple negative as a surrogate for basal-like $[15,19]$. Therefore, this study focused on the basal-like tumors that are triple negative; hence the term $\underline{\mathbf{b}}$ asal-like and triple-

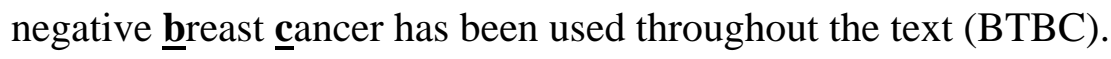

BTBC tumors express genes that are associated with myoepithelial cells such as cytokeratins (CK 5/6, CK 14, CK17), P-cadherin, and smooth muscle markers ( $\alpha$-smooth muscle actin) [20]. Most of BTBC are positive for epidermal growth factor receptor (EGFR) and protein tyrosine kinase Kit (c- Kit) [14]. Currently, BTBC is the most challenging subtype of breast cancer as there are no targeted therapies available. As such, chemotherapy is the only form of systematic treatment available for patients with this subtype. Although some patients respond very well to chemotherapy initially they eventually develop resistance leading to disease recurrence and 
fatality [15]. There are several potential targeted therapies that have been identified and are currently in preclinical and clinical trials. Some of the drug targets being explored are the receptor tyrosine kinases that include EGFR, c-Kit, hepatocyte growth factor receptor (HGFR), and Insulin-like growth factor I receptor (IGF-IR), and the cytoplasmic protein kinase c-Src. In addition, efforts are underway to target protein kinases that are involved in the signaling transduction pathway of the mitogen activated protein kinase (MAPK), and the phosphatidylinositol-3-kinase/ Serine threonine kinase Akt (PI3K/Akt) pathways [12, 14, 15, 21]. Unfortunately, preliminary results from the clinical trials indicate it is unlikely that a single agent will serve the purpose of effectively treating all patients. It is most likely that a combination therapy of targeted and general cytotoxic agents will be the most effective way in treating patients with this subtype [15].

Despite the ongoing efforts, no effective targeted therapy has been developed yet. Therefore, research on new targets is warranted. This study has focused on the Src homology 2 (SH2) containing phosphatase 2 (SHP2) which is a well-known regulator of receptor tyrosine kinaseinduced signaling, especially that of epidermal growth factor receptor (EGFR) [22]. 


\subsection{The Structure of SHP2 (PTPN11) and activation}

The Src homology 2 (SH2) containing phosphatase 2 (SHP2) is a cytoplasmic protein tyrosine phosphatase (PTP), encoded by the PTPN11 gene in humans, and is ubiquitously expressed in various tissue and cell types. It belongs to a highly conserved subfamily of cytoplasmic tyrosine phosphatase that includes itself and its structural homologus SHP1 [23-25]. The invertebrate homologus of SHP2 include corkscrew in Drosophila and Ptp-2 in C. elegans [25]. Structurally, SHP2 consists of two tandem-arranged SH2 domains at the amino-terminus (N-SH2 and C-SH2 respectively), a single tyrosine phosphatase domain (PTP) carboxyl-terminal to the SH2 domains, and a C-terminal tail that contains two tyrosine residues and a proline- rich motif with unknown function [24, 26, 27]. The SH2 domains have two important functions. 1) They are required for recruitment of SHP2 to the micro-domain of its substrates; 2) and they regulate the enzyme activity particularly accomplished by the N-SH2 [23, 25, 26].

The crystal structure of SHP2 revealed that SHP2 is auto-inhibited by intramolecular interactions between the N-SH2 and PTP domains under basal condition, blocking substrate access and the enzyme activity $[27,28]$. Binding of a phosphorylated tyrosine (pY) to the SH2 domains induces conformational changes in the N-SH2 domain, exposing the PTP domain, and activating the enzyme as shown in (Fig.1). 


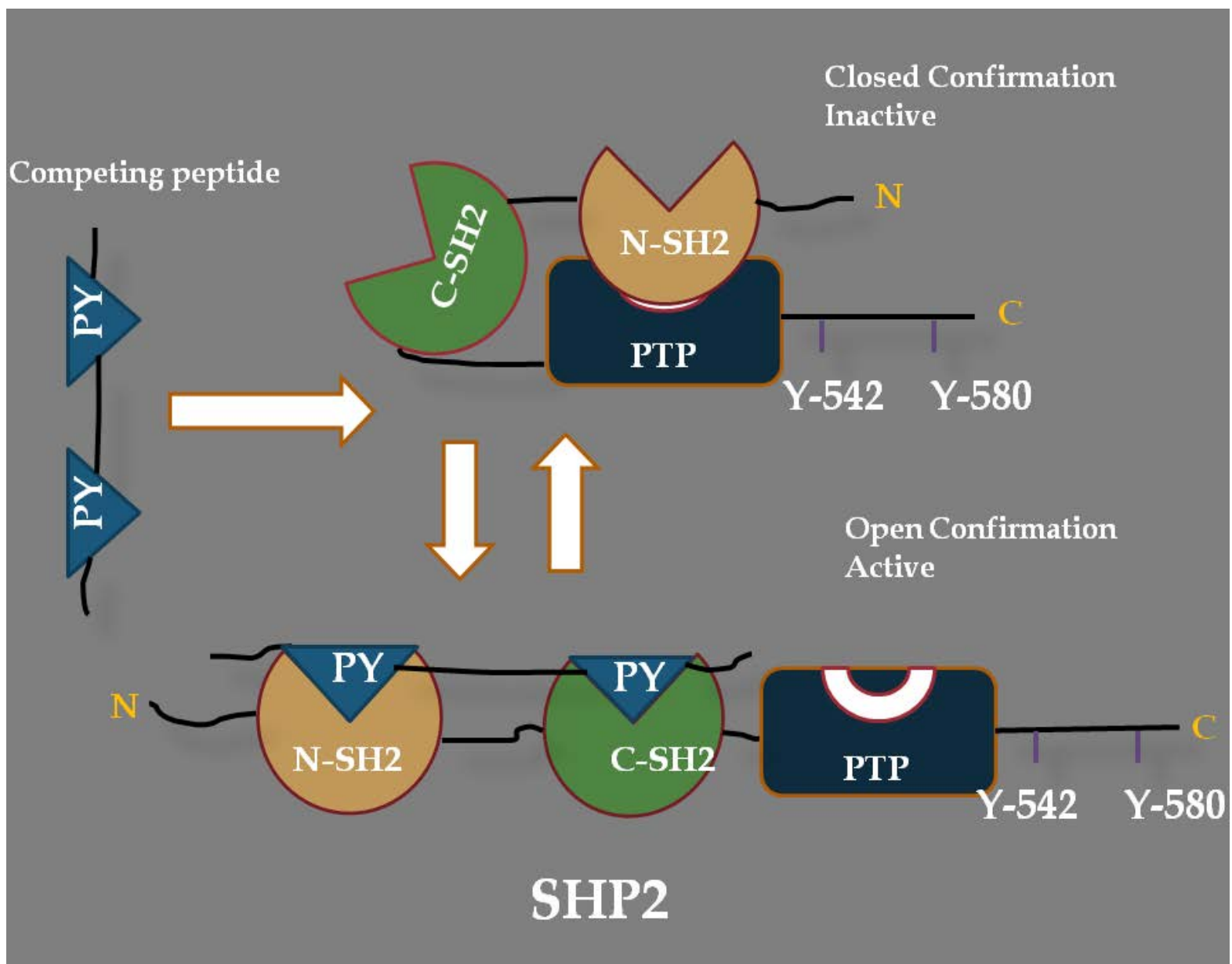

Figure (1): Schematic of SHP2 activation: In the absence of growth factor stimulation SHP2 is maintained in a closed confirmation (inactive) by intramolecular interaction between the N-SH2 domain and the PTP domain. Binding of a competing peptide with double p-Tyr-residues to the N-SH2 and C-SH2 domains causes SHP2 to assume open confirmation with subsequent activation of the PTP domain. 


\subsection{SHP2 (PTPN11) in cell signaling}

SHP2 has emerged as one of the rare PTPs that in many cases positively enhances signal transduction rather than inhibiting [27]. Several biochemical and genetic studies indicate that SHP2 is widely involved in transducing signals from various growth factors, cytokines, hormones, and extracellular matrices (ECM) [23, 25, 27, 29, 30]. Therefore, SHP2 has been implicated to function in the coordination and integration of several biological processes such as cell growth, survival, migration, differentiation and cell death [23, 29]. A great body of evidence demonstrates that SHP2 is a positive regulator (signal-enhancing) of the Ras/MAPK pathway downstream of RTKs and cytokine receptors [23, 24]. As such, SHP2 is required for full and sustained activation of the Ras/MAPK pathway [27, 30]. For example, in fibroblast cells that express a mutant SHP2 lacking the N-terminal SH2 domain, which is believed to be a loss of function mutation (SHP2-/-), the MAPK activation in response to epidermal growth factor (EGF), insulin like growth factor (IGF), platelet derive growth factor (PDGF), and fibroblast growth factor (FGF) was lower or at least unsustained compared to wild type expressing cell [27]. Furthermore, microinjection of catalytically inactive mutant of SHP2 mRNA in Xenopus embryos blocked FGF-induced stimulation of extracellular-signal regulated kianse (ERK) activation [31, 32]. Also, overexpression of catalyically inactive SHP2 mutant in 3T3 cells blocked insulin-induced activation of mitogen activated protein kinase (MAPK) [33].

Different mechanisms have been suggested for SHP2 regulation of the Ras/MAPK pathway. First, SHP2 can dephosphorylate the binding sites for the GTPase-activating protein RasGAP on RTKs (e.g. EGFR and PDGFR) and scaffolding molecules such as Gab protein and receptor substrates (e.g. insulin and fibroblast receptor substrates) [25, 30, 34]. Second, SHP2 promotes activation of the Ras/MAPK pathway by dephosphorylating Sprouty, a known negative regulator 
of this signaling pathway. Dephosphorylation of Sprouty by SHP2 negatively regulates its activity and enhances the signaling through the Ras/ MAPK pathway [27, 30]. Furthermore, SHP2 has been suggested to activate the Ras/MAPK pathway by regulating Src activity either through direct dephosphorylation or by inhibiting the recruitment of the Src negative regulator Csk [25, 30]. There is definitely no shortage in the suggested mechanisms as to how SHP2 activates the Ras/MAPK pathway; however, one should keep in mind that receptor and/or cell type dependence could be the reason for the emergence of several candidates [30].

SHP2 has also been suggested to regulate the (PI3K/Akt) and RhoA pathways. Receptor type or cell context determines whether SHP2 acts positively or negatively [35, 36]. For example, it has been shown that SHP2 associates with the P85 subunit of PI3K, leading to its activation upon stimulation with IGF-1 and PDGF in glioblastoma and fibroblast cells [35, 36]. However, others have shown that SHP2 acts as a negative regulator of the EGF-induced PI3K activation in fibroblasts that express the mutant form of SHP2 (SHP2-/-) [35, 36]. For instance, upon EGF stimulation of the (SHP2-/-) fibroblasts there is an increased association between P85 subunit and Gab1, suggesting a mechanism where SHP2 negatively regulates the PI3K pathway by dephosphorylating a P85 binding sites on Gab1 [36].

SHP2 has also been implicated in the regulation of Janus kinase/ signal transducers and activators of transcription (JAK/STAT) and the nuclear transcription factor (NF- $\mathrm{kB}$ ) downstream of cytokine receptors. Previous studies demonstrated that SHP2 positively regulates the NF- $\mathrm{KB}$ activation induced by IL-1 and tumor necrosis factor (TNF), which leads to IL-6 secretion. In contrast to its role in NF- $\mathrm{kB}$ activation, SHP2 plays a negative role in the induction of the JAK/STAT pathway induced by interferon [37]. In doing so, SHP2 appears to function as a prosurvival factor protecting the cell from the cytotoxic effect of interferon. In general, the 
combined effect of SHP2 on both NF-kB and interferon-stimulated JAK/STAT pathway could provide a mechanism into how SHP2 exerts its protective effect against cell death [38].

Recently, SHP2 has been implicated in Wnt signaling gene expression. The suggested SHP2 substrate that mediates the effect in Wnt signaling is parafibromin/Cdc73, a component of the nuclear RNA polymerase II-associated factor (PAF) [39]. Dephosphorylation by SHP2 converts parafibromin from being a trans-suppressor of c-myc and cyclin-D1expression into an activator of Wnt signaling gene expression [39]. Furthermore, SHP2 has been implicated in the increased $\beta$-catenin nuclear localization via inhibition of its interaction with $\alpha$-catenin [40].

In summary, SHP2 appears to function in various signaling pathways that include Ras/MAPK, PI3K, JAK/STAT, NF-кB, and Wnt signaling. These observations imply a combined signaling function for SHP2 in that it may act at multiple signaling sites at the same time to coordinate and integrate multiple cellular processes such as, cell growth, survival, motility, and cell death [29].

\subsection{SHP2 in transformation and cancer}

SHP2 is the first human phosphatase that was found to act as a proto-oncogene. Somatic PTPN11 mutations that disturb the auto-inhibited state and activate the enzyme have been linked to different types of leukemia [41]. For example, D61Y and E76K are the most common activating mutations in SHP2 occurring in sporadic juvenile myelomonocytic leukemia (JMML) and accounting for approximately $35 \%$ of the cases [42, 43]. These SHP2 mutations affect the $\mathrm{N}-\mathrm{SH} 2$ domain residues that are involved in the auto-inhibited state causing the enzyme to assume an active state. SHP2 activating mutations are also found in other myeloid neoplasms but in lower incidences. These include $5-10 \%$ of childhood myelodysplastic syndrome (MDS), 
7\% of B cell-acute lymphocytic leukemia B-ALL, some cases of acute mylogenous leukemia (AML), and chronic myelomonocytic leukemia (CMML) [28, 41, 42, 44].

PTPN11 somatic mutations are rare in solid tumors; nevertheless, PTPN11 activating mutations have been detected in a very low prevalence in breast cancer, neuroblastoma, lung adenocarcinoma, melanoma, and colorectal cancer [44]. While mutations affecting SHP2 in solid tumors are infrequent and very rare, wild type SHP2 is an essential component positively enhancing the signaling pathways downstream of growth factor receptors and proto-oncogenes that have significant contributions in cancer [42].

SHP2 has also been implicated in the severe gastritis and gastric carcinoma caused by the bacterium Helicobacter pylori that have the cytotoxin associated Antigen A (CagA) gene [42, 45]. The CagA protein, once delivered into the infected gastric epithelial cells, undergoes tyrosine phosphorylation by Src family kinases (SFK) on EPIYA motifs, which provides a high affinity binding site for SHP2 [45]. Therefore, tyrosine phosphorylated CagA recruits and activates SHP2. Once SHP2 is activated, it acts to transmit positive signals that promote cell growth and motility. In fact, several studies demonstrate that the virulence factor CagA, acting through SHP2, is the critical mechanism by which CagA promotes gastric carcinoma $[28,45]$. For example, knocking down SHP2 diminishes the CagA-induced hummingbird phenotype, which is characterized by enhanced spreading and elongation in gastric epithelial cells [45].

Similarly, aberrant expression of normal scaffolding proteins like Gab2 can contribute to oncogenesis by activating wild type SHP2. Indeed, Gab2 is frequently overexpressed in breast cancer, and several experimental studies showed that Gab2, acting through SHP2, can promote excessive proliferation of mammary epithelial cells and can mediate transformation and tumorigenesis induced by HER2 [42, 46]. 
Most importantly, previous work has demonstrated that SHP2 expression is upregulated in infiltrating ductal carcinoma (IDC) [47]. SHP2 was overexpressed in approximately $79 \%$ and 67\% of HER2-positive and HER-negative IDC tumors, respectively, with strong association to higher tumor grade and lymph node metastasis [47]. Moreover, SHP2 has been shown to promote breast cancer cell transformation, and its inhibition leads to mesenchymal to epithelial transition (MET), the opposite of EMT (epithelial to mesenchymal transition) [48].

Very recently, an important function for SHP2 in promoting mammary tumorigenesis in vivo has been established. It has been shown that inhibition of SHP2 by shRNA in breast cancer cells suppresses tumor growth in animal xenograft models [49].

To sum up, while SHP2 mutations are infrequent in solid tumors, strong evidence has implicated the wild type SHP2 activation either by overexpression or by other mechanisms (e.g. activation by protein tyrosine kinases) in transformation and tumor growth of cancer cells.

\subsection{Hypothesis and objectives}

Earlier work has shown that SHP2 is overexpressed in approximately $75 \%$ of IDC of the breast with strong association to higher tumor grade and lymph node metastasis [50]. Furthermore, it has been shown that SHP2 is required for maintaining the transformed phenotype and for sustaining the EMT process in breast cancer cell lines that overexpress EGFR or HER2 $[48,50]$. Altogether, these data imply a significant role for SHP2 in breast cancer.

BTBC presents the most challenging subtype of breast cancer to treat. Therefore, identifying and characterizing new therapeutic targets is urgently needed. Based on the previous evidence implying a role for shp2 in breast cancer oncogenesis, we hypothesize that SHP2 is important for 
the transformation and tumorigenic potential of breast cancer cell lines typical to BTBC tumors. Therefore, this study was aimed at investigating the following specific objectives:

I. Produce stably infected breast cancer cell lines that constitutively express antiSHP2 shRNA from BTBC cell lines (e.g. MDA-MB-231 and MDA-MB-468).

II. Investigate if SHP2 inhibition impacts cell proliferation, transformation, and invasion in cell culture conditions.

III. Determine if inhibition of SHP2 abolishes the tumorigenic and metastatic potential of the BTBC cells in NOD/SCID mice.

IV. Study the signaling pathways affected by SHP2 depletion

\subsection{Significant contributions}

In this study we have shown that SHP2 promotes the transformation and tumorigenic potential of BTBC cells under cell culture and in vivo condition. We also provide evidence showing a positive role for SHP2 in the metastatic potential of BTBC cells. The results show that tumor growth of basal type breast cancer cell lines MDA-MB-468 and MDA-MB-231 depends on SHP2. Depletion of SHP2 protein suppressed anchorage-independence growth, cell proliferation, wound healing, and the invasive phenotype of BTBC cells. Mechanistically, SHP2 depletion decreased $\beta$-catenin levels, increased p27 expression, and was necessary for EGFinduced sustained Ras activation. We also show that SHP2 is required for the self-renewal 
capacity of the tumor initiating cells (TICs) in BTBC cells. Collectively, our results provide new insights into the signaling networks promoting tumor progression and metastasis in BTBC as well as a rationale for considering SHP2 as a potential therapeutic target in BTBC. 


\section{MATERIALS AND METHODS}




\subsection{Reagents and cell culture}

The breast cancer cell lines MDA-MB-468 and MDA-MB-231 were purchased from ATCC. Cells were grown in Dulbecco’s Modified Eagle Medium (DMEM) supplemented with 10\% fetal bovine serum, non-essential amino acids, and an antimycotic/antibiotic solution (Mediatech, Inc.). Cells were maintained at $37^{\circ} \mathrm{C}$ in $5 \% \mathrm{CO}_{2}$ humidified atmosphere. Primary antibodies used in this study included anti- $\beta$-catenin with 1:1000 dilution (catalog \# sc-7963), anti-pan ERK2 with 1:1000 dilution (catalog \# sc-154), and anti-P27 with 1:1000 dilution (catalog \# sc528) purchased from Santa Cruz. The anti- $\beta$-actin with 1:3000 dilution (catalog \# A5441) was purchased from Sigma and anti-PTP1D with 1:1000 dilution (SHP2) (catalog \# sc-7384) was from Pharmagen. Anti- pan AKT with 1:1000 dilution (catalog \# 06-558) and anti-GST with 1:2000 dilution (catalog \# 05-311) were from Upstate Technology. Anti- MMP9 with 1:1000 dilution (catalog \# AB13458) was from Millipore, while anti-Ras with 1:1000 dilution (catalog \# 610002) was obtained from Transduction Laboratories. Secondary antibodies used included sheep anti-mouse and goat anti-rabbit conjugated to horseradish peroxidase purchased from Amersham. Matrigel was purchased from BD Bioscience (Bedford, MA), and the EdU Alexa Flour 647 was from Molecular Probes (Invitrogen, OR).

\subsection{Preparation of cell and tissue lysates}

Cell lysates were collected by washing cells twice with cold $1 \mathrm{X}$ phosphate buffered saline (PBS) followed by incubation on ice for 20 minutes with $500 \mu \mathrm{l}$ of cell lysis buffer (20 mM TrisHCl, pH 7.4, 150 mM NaCl, 50 mM NaF, 1 mM EDTA, 10\% glycerol, 1\% Triton X-100, 1 mM sodium orthovanadate, $1 \mathrm{mM}$ PMSF, $1 \mu \mathrm{g} / \mathrm{ml}$ aprotinin, $1 \mu \mathrm{g} / \mathrm{ml}$ leupeptin). Cells were scraped 
to bring cells into suspension. To collect lysates from tumor samples, tissues were dissected, and then quickly mixed with cell lysis buffer, minced into small pieces on ice. Samples were sonicated at low setting (power setting to 2) and then incubated on ice for 30 minutes. Lysates were cleared by centrifugation at $13,000 \mathrm{rpm}$ for 20 minutes at $4^{\circ} \mathrm{C}$. Supernatant was then used for analysis.

\subsection{Polyacrylamide gel electrophoresis (PAGE) and immunoblotting analysis}

Equal amounts of lysates were resolved with $8 \%$ or $10 \%$ denaturing polyacrylamide gel (SDS-PAGE). Separated proteins were transferred to nitrocellulose membranes (Thermo scientific, IL), blocked with 3\% bovine serum albumin (BSA) in Tris-Buffered Saline Tween 20 (TBST) at room temperature for 1 hour, and then incubated with a primary antibody in TBST either overnight at $4^{\circ} \mathrm{C}$ or for 2 hours at room temperature. After washing 3 times with TBST buffer (25 mM Tris.HCl, pH 7.4, $150 \mathrm{mM} \mathrm{NaCl,} \mathrm{0.1 \%} \mathrm{Tween} \mathrm{20)} \mathrm{the} \mathrm{membranes} \mathrm{were}$ incubated with a secondary antibody in 5\% milk for 1 hour at room temperature. Chemiluminescence detection was used to visualize proteins (Perkin Elmer).

\subsection{Short hairpin ribonucleic acid (shRNA) construction and stable cell line production}

Short double-stranded oligonucleotides for SHP2 protein inhibitionwere custom-synthesized (Integrated DNA Technology) and were ligated into the BamHI and EcoRI site of the lentivirus pLSL-Puro (a gift from Dr. Peter Chumskoy, Cleveland Clinic Foundation). The targeting sequences 5’-GTATTACATGGAACATCAC-3' and 5’-GAAGAATCCTATGGTGGAA-3’ as previously described [51]. Briefly, after ligation overnight at $16^{\circ} \mathrm{C}, X L$-blue bacteria were 
transformed with the ligated vector. Transformed bacteria with Ampicillin resistance were grown on agar plate and used to inoculate a small volume culture of Luria broth (LB) containing 100 $\mu g / m l$ Ampicillin. The culture was then placed in a shaker at $37^{\circ} \mathrm{C}$ and grown overnight. The bacterial culture was then pelleted using a centrifuge (6000 xg/ 15 minutes at $\left.4{ }^{\circ} \mathrm{C}\right)$, and the plasmid DNA was purified using Miniprep kit according to the manufacturer's instructions (Qiagen). Inserts were verified by DNA sequencing. Positive clones were used to inoculate a larger volume of LB/Ampicillin (100 $\mu \mathrm{g} / \mathrm{ml})$, and large scale DNA plasmid preps were obtained using Qiagen Midiprep kit.

For lentiviral transduction, three plasmids (transfer vector with expression construct, the packaging plasmid pCMV, and the VSV-G envelope protein expressing plasmid) were mixed in a ratio of 3:2:1 and transduced into 293T packaging cells using the Turbofect reagent (Fermentas) according to the manufacturer's protocol. After 48 hours, supernatants containing the recombinant virus were collected every 24 hours and were centrifuged at $1500 \mathrm{rpm}$ for 5-10 minutes to remove dead cells. The virus-containing medium was used along with $3 \mu \mathrm{g} / \mathrm{ml}$ polybrene to infect BTBC cell lines by incubating the cells with the virus supernatant at $37^{\circ} \mathrm{C}$ for a minimum of 6-8 hours. Cells were treated with $4 \mu \mathrm{g} / \mathrm{ml}$ puromycin $48-72$ hours post-infection to select for cells with genomic incorporation of the expression vector. Lentivirus expressing a short hairpin targeting luciferase was used as a control in this experiment. Anti-SHP2 immunoblotting was used to confirm the level of SHP2 inhibition.

\subsection{Cell proliferation assay}

The 5-ethynyl-2'-deoxyuridine (EdU) proliferation assay was performed as described [52] 
with slight modifications. In brief, cells were seeded at $3 \times 10^{5}$ per well in six-well plates, then synchronized by adding DMEM medium containing 2\% serum for 8 hours. $10 \mu \mathrm{M}$ EdU was added to an approximately $40-50 \%$ confluent cells in each well for 24 hours. Non-treated cells served as controls. To detect the amount of EdU incorporated into the DNA, the Click-iT EdU Alexa Flour 647 Cell Proliferation Assay Kit (Molecular Probes, Invitrogen, OR, USA) was used according to the manufacturer's instructions. Briefly, $0.5 \times 10^{6}$ cells were harvested by trypsinization, washed twice with PBS containing $1 \%$ bovine serum albumin (BSA), then fixed in $100 \mu \mathrm{l}$ Click-iT fixative for 15 minutes at room temperature in the dark. For permeabilization, cells were washed twice in a saponin-based reagent. The Click-iT EdU reaction cocktail was prepared according to the manufacturer's instructions and $500 \mu \mathrm{l}$ per $0.5 \times 10^{6}$ cells was added to the cell pellet. After 30 minutes of incubation at room temperature in the dark, cells were washed and analyzed using flow cytometry.

\subsection{Monolayer -wound healing assay}

To evaluate the impact of SHP2 inhibition on BTBC cells wound healing in vitro, a standardized scratch assay was used. In detail, cells were grown to confluence in $6 \mathrm{~cm}$ dishes. Then the media was aspirated to remove floating dead cells, and replaced with fresh media. A guiding arrow was also drawn on the bottom of the plate to orient pictures. Two different scratches were made using a P200 pipette tip, and the fields were visualized and photographed using an Olympus IX71 microscope equipped with an Olympus DP30BW digital camera. Photos of the scratches were taken at 0,8 , and 12 hours. 


\subsection{Cell invasion assay}

To evaluate the impact of SHP2 inhibition on the invasive properties of BTBC cells, the dye quenched collagen IV (DQ collagen IV) served as a substrate in this assay. Multiple fluoresceins are bound to collagen IV (Molecular Probes) but are quenched in the intact state due to the proximity of each fluoresceine residues to one another. Collagen degradation by proteolysis generates a fluorescent signal that can be used as a read out for invasion. In detail, Matrigel was mixed with $25 \mu \mathrm{g} / \mathrm{ml}$ DQ collagen IV. Then the mixture was used to coat 4-well chamber slides (BD Falcon) which were left at $37^{\circ} \mathrm{C}$ for 15 minutes to solidify. 25,000 cells were resuspended in $2 \%$ Matrigel mixed with DQ collagen IV and were seeded in the chambers. Cells were observed over a period of 48 hours for the development of fluorescence using an Olympus IX71 microscope equipped with an Olympus DP30BW digital camera.

\subsection{Mammosphere assay}

To assess the impact of SHP2 inhibition on the tumor initiating cells (TICs), the mammosphere assay was performed as described previously [53] with slight modifications. Briefly, cells were seeded at $1 \times 10^{4}$ cells per well in a six-well Ultra Low Attachment Plate (Corning, NY) and grown for 7 -10 days in serum free medium supplemented with B27 and 20 ng/ml EGF. Cells were fed once every 3 days with $1 \mathrm{ml}$ serum free medium supplemented with growth factors. The impact of SHP2 inhibition on mammosphere formation was determined by counting the acolonies $50 \mu \mathrm{m}$ or more in diameter. For serial passaging, mammospheres were harvested by gentle centrifugation at $800 \mathrm{rpm}$ for 5 minutes, dissociated to single cells with trypsin treatment, and $1 \times 10^{4}$ cells were re-plated in a six-well plate and were cultured for 
additional 10 days. Resulting mammospheres were counted as above.

\subsection{Anchorage-independent growth assays}

Soft agar colony assays were performed as previously described [48]. Briefly, $6 \mathrm{~cm}$ cell culture plates were coated with $0.6 \%$ agar in growth medium. $1 \times 10^{5}$ cells were suspended in growth medium mixed with melted agar to a final concentration of $0.4 \%$, then poured onto the agar bed. A minimum of 10 fields per plate were counted, and the size cutoff was $>50 \mu \mathrm{m}$ in diameter. Colony size was measured under a microscope, and phase contrast pictures were taken using an Olympus IX71 microscope equipped with an Olympus DP30BW digital camera.

\subsection{Ras activation assay}

Ras activation was determined by affinity precipitation with the Ras binding domain of Raf-1 fused to glutathione-S-transferase (GST-RBD) as described previously [34]. Briefly, transformed bacteria with the pGEX-GST-RBD plasmid were inoculated in a culture of $50 \mathrm{ml}$ Luria broth (LB) containing $100 \mu \mathrm{g} / \mathrm{ml}$ Ampicillin, then placed in a shaker at $37^{\circ} \mathrm{C}$ and grown overnight. The culture was then transferred to $500 \mathrm{ml} \mathrm{LB}$ and the growth was continued for 90 minutes (reaching an OD $600 \mathrm{~nm}$ of 0.8 ). $200 \mu \mathrm{M}$ of Isopropyl b-D-thiogalactopyranoside (IPTG) was added and incubated for 2 hours to induce the fusion protein expression. The bacterial culture was then pelleted by centrifugation $\left(5000 \mathrm{rpm} / 10\right.$ minutes at $\left.4{ }^{\circ} \mathrm{C}\right)$, then resuspended in 15-20 ml bacterial lysis buffer (20 mM Tris-HCl, pH 8.0, $150 \mathrm{mM} \mathrm{NaCl,} 1 \%$ Triton X-100, 10\% glycerol, 1\% NP-40, 2 mM EDTA, 1 mM PMSF, 1 gg/ml aprotinin, $1 \mu \mathrm{g} / \mathrm{ml}$ leupeptin). Lysis was achieved by sonication by pulsing 3 times for 30 seconds for each sample, 
until samples become clear (Amplitude knob setting at 37\%), and the lysate was cleared by centrifugation (10000rpm/10 minutes at $\left.4{ }^{\circ} \mathrm{C}\right)$. The resulting GST-RBD fusion protein was purified on glutathione sepharose beads ( $20 \mu$ l packed volume per sample, GE Healthcare) by tumbling for 1 hour at $4{ }^{\circ} \mathrm{C}$, followed by washing 3 times with bacterial lysis buffer and 2 times with cell lysis buffer. Breast cancer cells were serum-starved overnight, then stimulated with 20 ng/ml of EGF in a time course manner for varying time points (10, 60, 120, 240 minutes). Cells were lysed by washing twice with cold $1 \mathrm{X}$ phosphate buffered saline (PBS) followed by incubation on ice for 20 minutes with $500 \mu$ l of cell lysis buffer $(20 \mathrm{mM}$ Tris-HCl, pH 7.4, 150 $\mathrm{mM} \mathrm{NaCl}, 50 \mathrm{mM} \mathrm{NaF}, 1 \mathrm{mM}$ EDTA, $10 \%$ glycerol, $1 \%$ Triton X-100, $1 \mathrm{mM}$ sodium orthovanadate, $1 \mathrm{mM}$ PMSF, $1 \mu \mathrm{g} / \mathrm{ml}$ aprotinin, $1 \mu \mathrm{g} / \mathrm{ml}$ leupeptin). Equal amounts were tumbled with GST-RBD bound to the glutathione sepharose beads for 1 hour at $4{ }^{\circ} \mathrm{C}$. Beads were washed three times with cold cell lysis buffer before mixing with $2 \mathrm{X}$ Laemmli sample loading buffer ( 0.125 M Tris-PH 6.8, 0.2M Dithiothrietol, 4 \% SDS, 20 \% glycerol, $0.02 \%$ Bromophenol blue), and boiling for 10 minute at $100{ }^{\circ} \mathrm{C}$. Samples were resolved on $12 \%$ SDSPAGE for immunoblot analysis. Then the separated proteins were transferred onto nitrocellulose membrane, blocked with 3\% BSA in TBST, and the amount of Ras- pull down was assessed using anti-Ras monoclonal antibody.

\subsection{Gelatin zymography assay}

MDA-MB-231 cells were grown in $6 \mathrm{~cm}$ dishes until 85-90\% confluency, then serumstarved for 24 hours before stimulation with $50 \mathrm{ng} / \mathrm{ml}$ EGF. Conditioned media was collected and concentrated using Amicon Ultra-4 centrifugal filter $(10 \mathrm{kDa})$ according to the 
manufacturer's instructions. The amount of concentrated media was normalized to the amount of protein in the total cell lysate. The concentrated media was mixed with a non-reducing SDS sample buffer without boiling and then loaded on a zymogram $10 \%$ gelatin gel (Novex EC6175BOX, Invitrogen). After electrophoresis, the gel was washed twice with 2.5\% Triton X100 using gentle agitation for 15 minutes. The gel was then washed in developing buffer (50 $\mathrm{mM}$ Tris base, $40 \mathrm{mM} \mathrm{HCl}$, and $200 \mathrm{mM} \mathrm{NaCl}, 5 \mathrm{mM} \mathrm{CaCl}_{2}$, 0.02\% (w/v) Brij 35) once for 30 min before overnight incubation at $37^{\circ} \mathrm{C}$ with gentle agitation. Next, the gel was stained with 0.5\% Coomassie Blue R250 in a mixture of 50\% methanol, $10 \%$ acetic acid, and $40 \%$ water for one hour at room temperature before destaining in the same mixture without the dye. Serum-free medium (SF) and regular medium (RM) were used as a negative and a positive control, respectively. Gelatinolytic activity was detected as a clear band against a blue background. The degree of digestion was measured using a laser scanning densitometer.

\subsection{Tumor xenograft growth}

Experiments involving animals were approved by the Animal Care and Use Committee of the West Virginia University. Mice used for this study were female nonobese diabetic/severe combined immune deficiency (NOD/SCID) mice aged 8-10 weeks obtained from the Jackson laboratory. Breast cancer cells were suspended in $100 \mu \mathrm{l}$ of a 1:1 mixture of growth media and matrigel (BD Biosciences) and were injected in the right fourth mammary fat pad. Mice injected with MDA-MB-468 received $1.5 \times 10^{6}$ cells (6 mice); while the mice injected with MDA-MB-231

received $2.5 \times 10^{6}$ cells ( 7 mice). Tumor sizes were measured with a caliper twice weekly, and tumor volume was calculated using the formula $\left(0.52 \mathrm{x}\right.$ length $\mathrm{x}$ width $\left.{ }^{2}\right)$ to estimate a spheroid 
volume [41]. Tumors and potential metastatic sites including lung, liver and brain were harvested after euthanization by cervical dislocation for further analysis. For histological purposes, frozen tumor sections were prepared, and then $7-\mu \mathrm{m}$ thick sections were cut with a cryomicrotome, and stained with hematoxylin and eosin.

\subsection{Statistical analysis}

All statistical analyses were performed using GraphPad Instat3 software. For comparisons of two groups of data, the Student's t-test was used with 95\% confidence intervals. Results were considered statistically significant at an error probability level of $\mathrm{p}<0.05$. 


\section{RESULTS}




\section{1 shRNA-mediated silencing of SHP2 expression}

The MDA-MB-231 and the MDA-MB-468 breast cancer cell lines were used as models to study the significance of SHP2 in BTBC. The MDA-MB-231 and the MDA-MB-468 breast cancer cell lines are basal-like and triple-negative as determined by expression of basal cytokeratins (CK5/6, 14 and 17), absence of HER2 overexpression (HER2-negative) and lack of nuclear accumulation of the estrogen and the progesterone receptors (ER/PR-negative) [54-56]. Furthermore, the MDA-MB468 cell line has an amplified EGFR gene [57, 58], and overexpresses the EGFR protein (3+ on IHC scale). The MDA-MB-231 cell line has no such genetic change, but still expresses an elevated amount of the EGFR protein (2+ on IHC scale) [59].

To investigate the impact of SHP2 inhibition on the tumorigenesis of BTBC cells, SHP2 expression was constitutively ablated by two independent shRNAs designated as shRNA-I and shRNA-II. Western blot analysis of total cell lysates showed that the expression of SHP2 protein level was effectively reduced in shSHP2-I and shSHP2-II expressing cells relative to the control in both cell lines (Fig.1A and C). Band density measurements confirmed that the SHP2 protein level was efficiently silenced by both shRNAs ( $\sim 95 \%$ by shSHP2-I and $\sim 80-90 \%$ by shSHP2-II) in both cell lines (Fig.1B and D). 


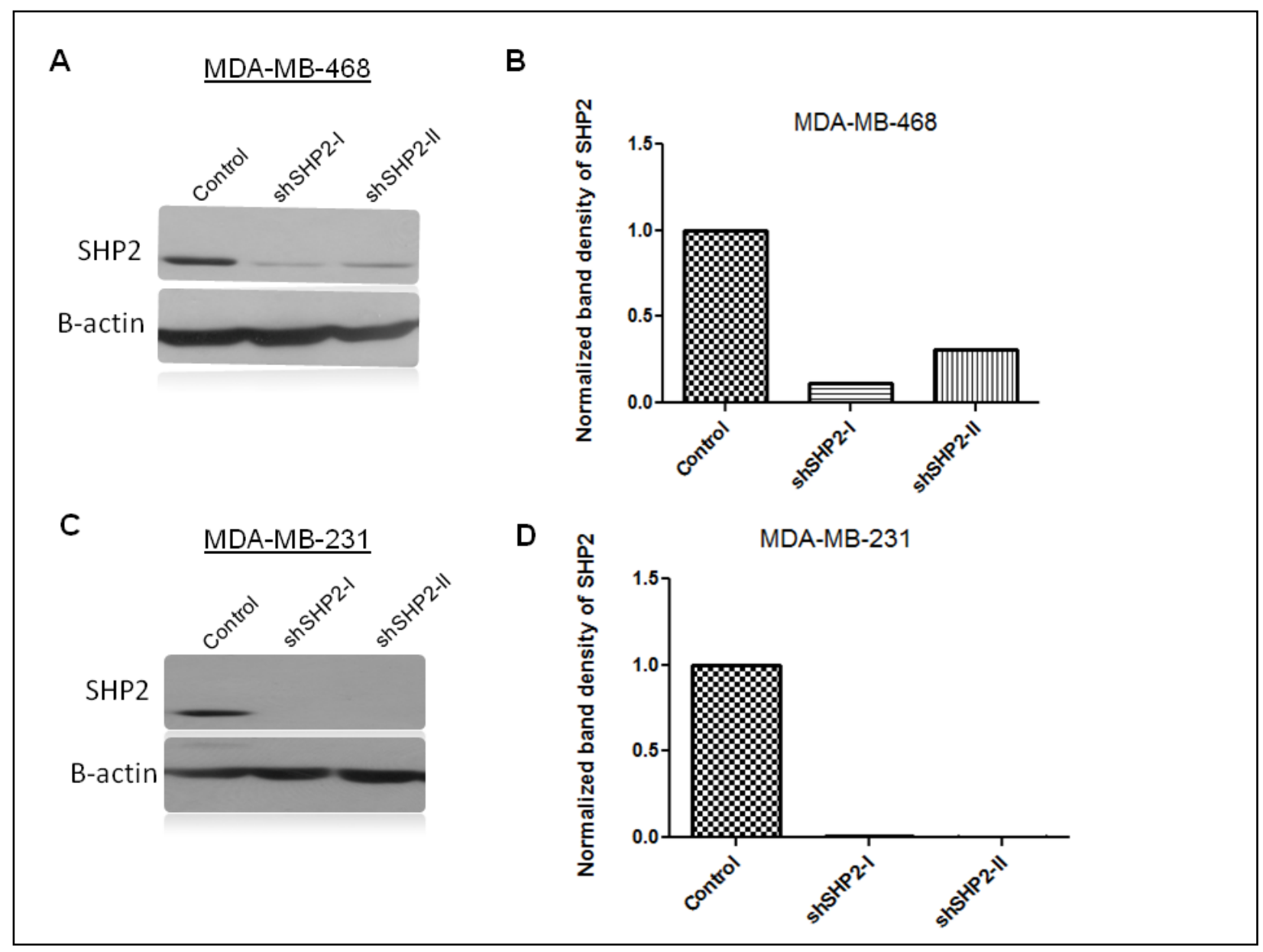

Figure 2: Western blot analysis of total cell lyastes prepared from the control and shRNA cells of the MDA-MB-468 (A) and the MDA-MB-231 (C). Bar graphs showing band density measurements of SHP2 expression in the control and shRNA cells derived from the MDA-MB468 (B) and the MDA-MB-231 (D). The bar graphs show the normalized level of SHP2 expression (normalized with $\beta$-actin levels). 


\subsection{SHP2 promotes BTBC cell proliferation}

In contrast to many other phosphatases, SHP2 promotes cellular processes such as cell proliferation and motility rather than inhibiting them. As a first step to study the role of SHP2 in BTBC, the impact of its inhibition on cell proliferation was investigated by the EdU (5-ethynyl2'-deoxyuridine) incorporation assay. EdU is a nucleoside analog of thymidine that gets incorporated into replicating DNA during S-phase. The EdU incorporation assay involves labeling of cells for 24 hours and detection by flow cytometery after counter staining with EdUspecific azide that is tagged with Alexa Flour 647. As shown in (Fig.3A), a larger percentage of the control cells incorporated EdU, compared to the shRNA cells. The bar graph further confirms that SHP2 depletion in MDA-MB-231 cells resulted in approximately 37\% loss of cell proliferation relative to the control (Fig.3B). 


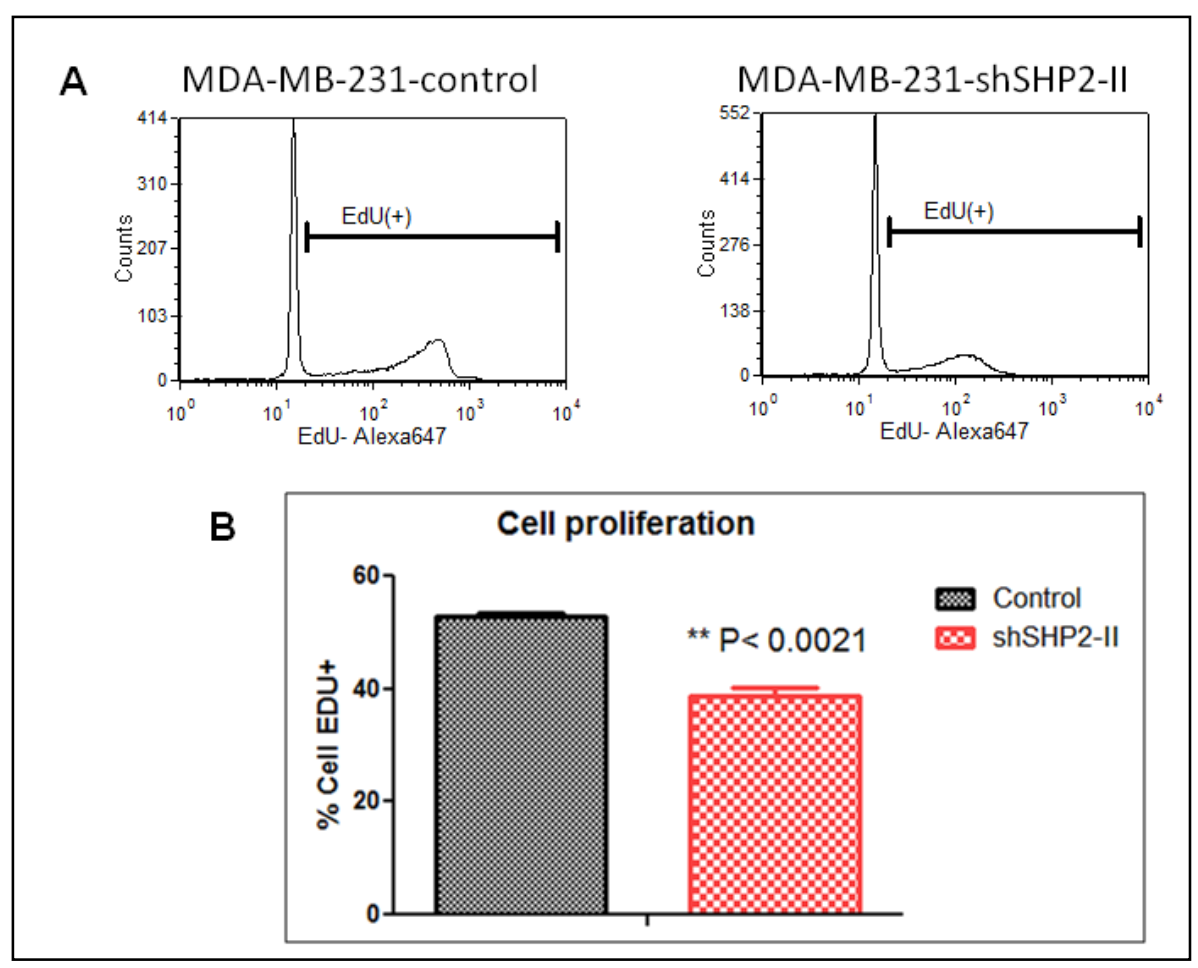

Figure 3: SHP2 knockdown suppresses cell proliferation in MDA-MB-231. (A) Representative histograms showing the number of cells stained with EdU- Alexa Flour 647. (B) Bar graph showing SHP2 depletion resulted in $37 \%$ loss of cell proliferation $(\mathrm{P}<0.0021)$. Data is represented as mean \pm SEM of triplicates. 


\subsection{SHP2 depletion suppresses anchorage-independent growth in BTBC cells}

Anchorage independent growth is one of the in vitro properties of a cancer cell that is utilized as a marker for cellular transformation. Therefore, it is routinely used to determine the impact of gene manipulation or drug treatment on cancer cell transformation. Seeding cells in soft agar suspends cells from attaching to the bottom of culture plates, providing anchorage-independent growth conditions. To evaluate a potential role for SHP2 in this process, approximately $1 \times 10^{5}$ cells from each cell line were seeded in $4 \%$ soft agar. After 3-4 weeks of incubation, the impact of SHP2 depletion on colony growth was determined by counting the number and/or measuring the size of the colonies that were larger than 50 um in diameter under a microscope. Representative micrographs showed that the MDA-MB-231 control cells formed more colonies in 3 weeks than the shRNA cells (Fig.4A). Similarly, the control cells derived from MDA-MB468 cells formed more colonies than the shRNA cells (Fig.4C). Determining colony number further confirmed that inhibition of SHP2 suppressed colony formation by approximately $80 \%$ in the MDA-MB-231 cells (Fig.4B) and by approximately 40\% in the MDA-MB-468 cells (Fig.4D). Although SHP2 inhibition had a relatively modest impact on colony number in the MDA-MB-468 cells, it had a significant impact on colony size; inhibition of SHP2 reduced colony size by approximately 62\% (Fig.4E). Collectively, these observations provide evidence showing that SHP2 is required for the anchorage independent growth of BTBC cells. 
A) MDA-MB-231 cells, soft agar assay, $10 \times$

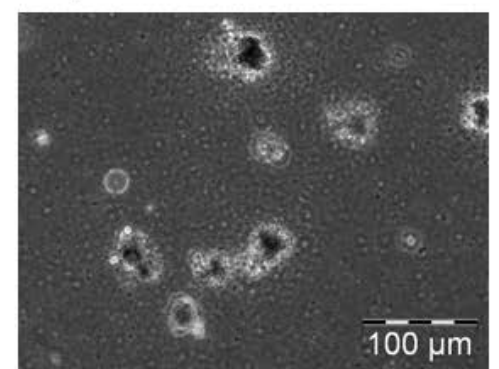

Control

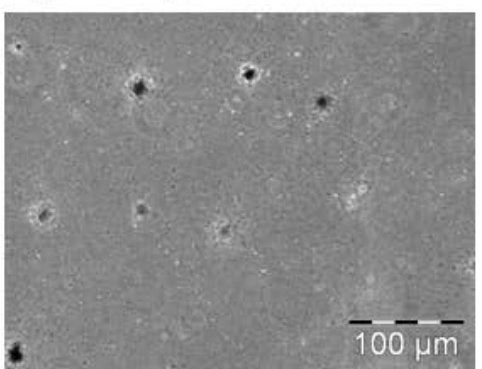

shSHP2-I

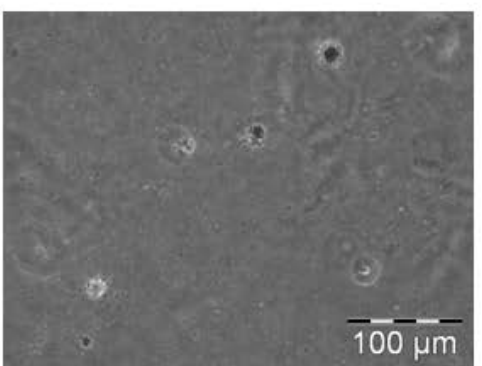

shSHP2-II

B) Colony

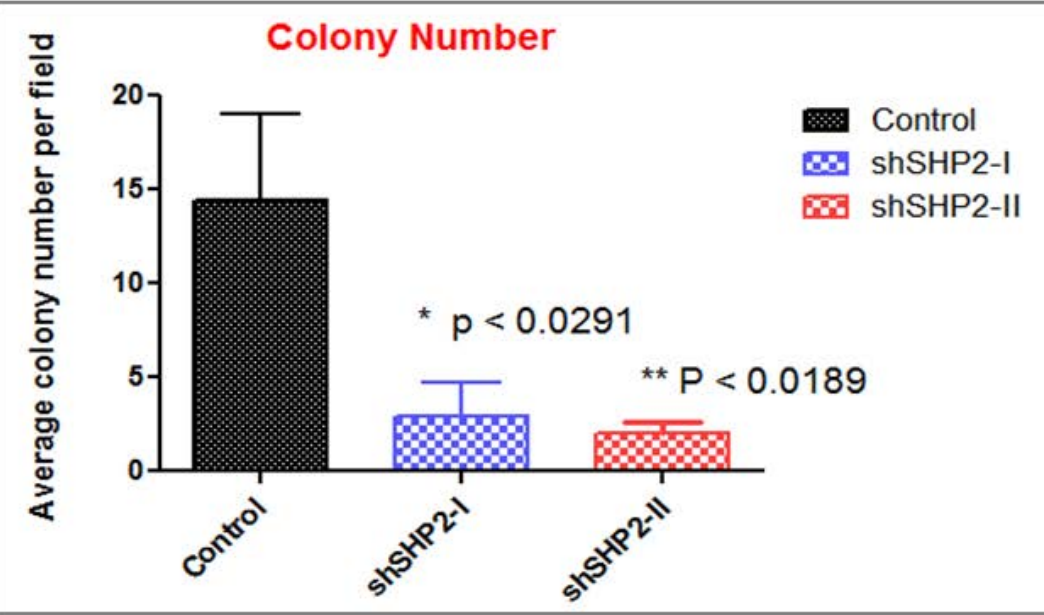




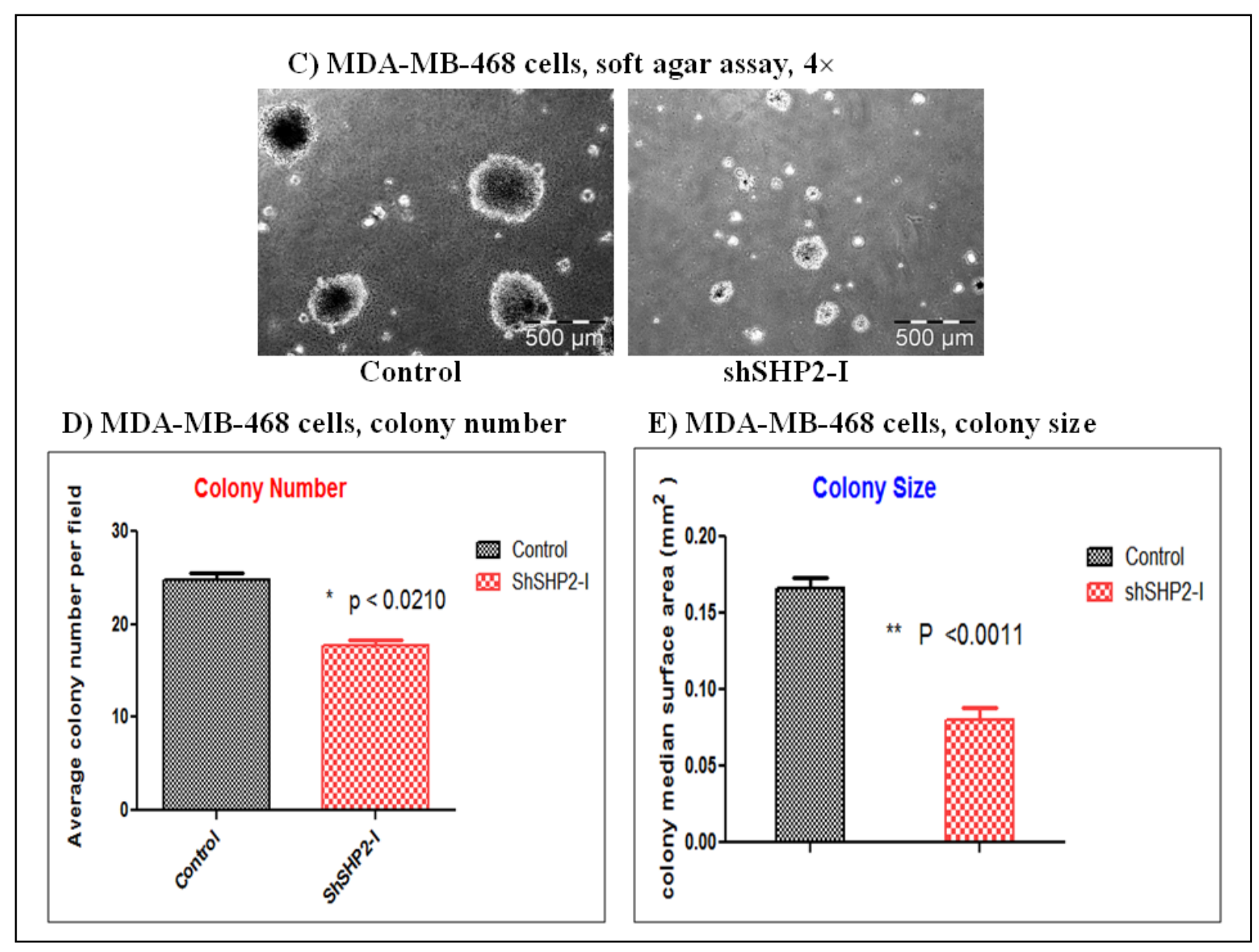

Figure 4: SHP2 suppresses anchorage-independent growth in the MDA-MB-231 and the MDA-MB-468 cells. Representative micrographs of MDA-MB-231 (A) and MDA-MB-468 (C) showing that the control cells formed more and larger colonies than the shRNA cells. Bar graphs showing colony number per field for the MDA-MB-231 (B) and for the MDA-MB-468 (D) cells. The bar graph in (E) depicts colony size for the MDA-MB-468 cells. Data is represented as mean \pm SEM from three independent experiments. 


\subsection{SHP2 is required for the migration of BTBC cells}

Previous work has demonstrated a function for SHP2 in regulating cell motility in other cell lines $[60,61]$. To further investigate the impact of SHP2 depletion in BTBC cell migration, wound-healing assays was performed on confluent cell monolayers. In agreement with previous observations, control cells derived from MDA-MB-231 cells filled the scratch wound within 24 hours, while the shRNA cells were unable to do so within the same period of time (Fig.5A). Similar results were obtained when these experiments were repeated in the MDA-MB-468 derived cells (Fig.5B). These results indicate an important role for SHP2 in BTBC cells migration.

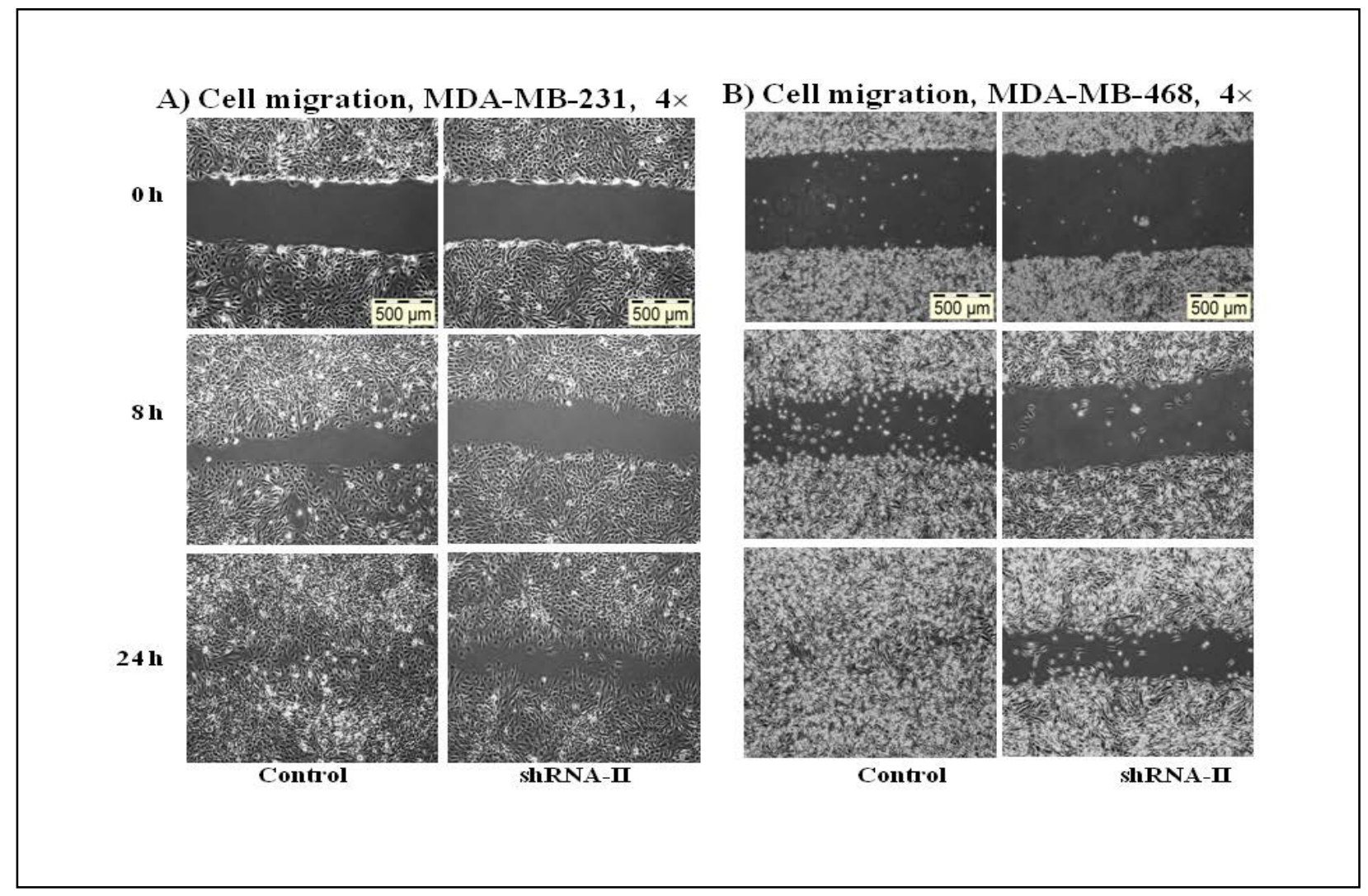

Figure 5: SHP2 inhibition suppresses migration in BTBC cells: Representative micrographs

showing impact of SHP2 inhibition on monolayer wound healing in the MDA-MB-231 (A) and the MDA-MB 468 (B) cells taken at the indicated time points. 


\subsection{The invasive property of BTBC cells is SHP2 dependent}

To investigate the contribution of SHP2 depletion on BTBC cell invasion, the 3D DQcollagen in Matrigel assay was used. When grown in 3D matrix, cells migrate and invade the surrounding ECM degrading DQ collagen IV. Degradation is measured by fluorescence microscopy as an accumulation of fluorescence products. Phase contrast microscopy images of MDA-MB-231 control cells showed that these cells grew as a cluster in the 3D matrix, with some cells extending a finger-like protrusion that were not observed in the shRNA cells (Fig.6A, lower panel). Furthermore, green fluorescent spots around the colonies were present in control cells and much lower fluorescence signals were observed in the shRNA cells (Fig.6A, upper panel). Similar results were observed using MDA-MB-468 cells (Fig.6B). Taken together, these results demonstrate that SHP2 is fundamental for the invasion process of BTBC cells, either through regulation of cell migration or proteolytic mediated ECM degradation. 
A) MDA-MB-231 cells, $10 \times, 24 \mathrm{~h}$

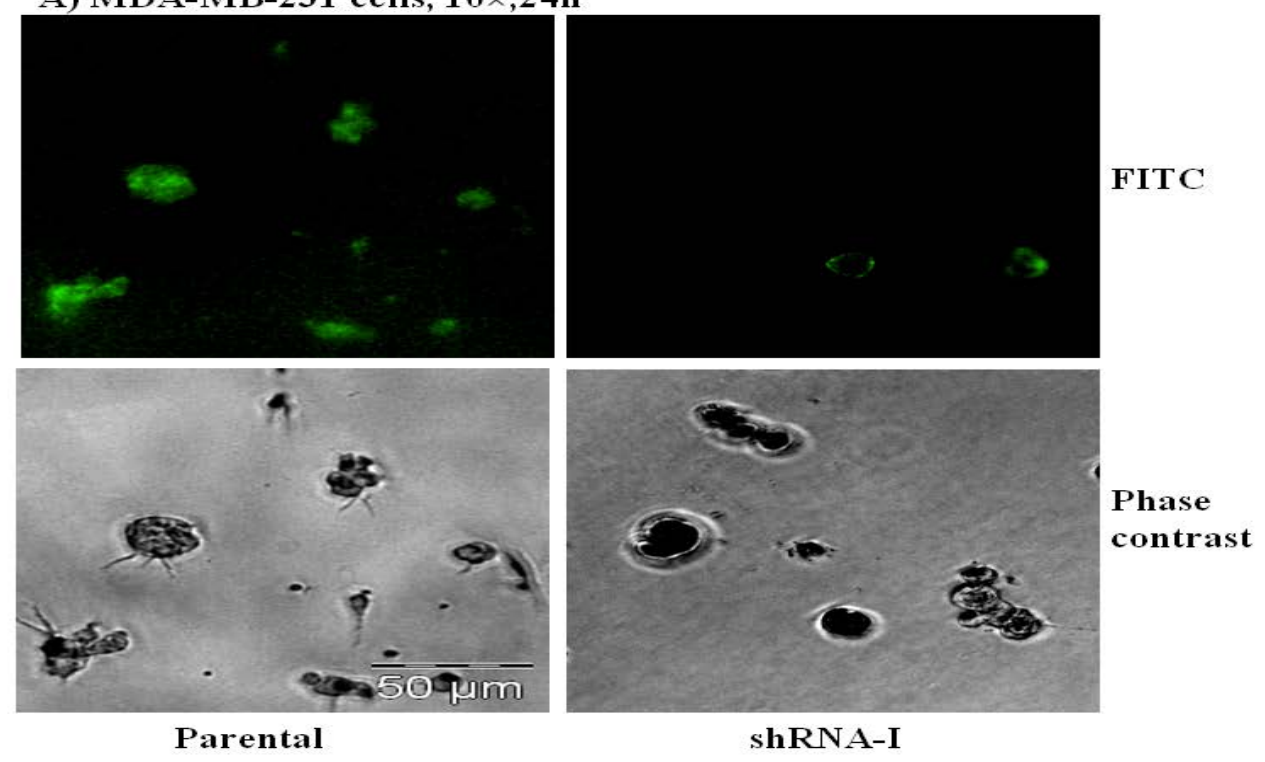

B) MDA-MB-468 cells, $10 \times, 24 \mathrm{~h}$
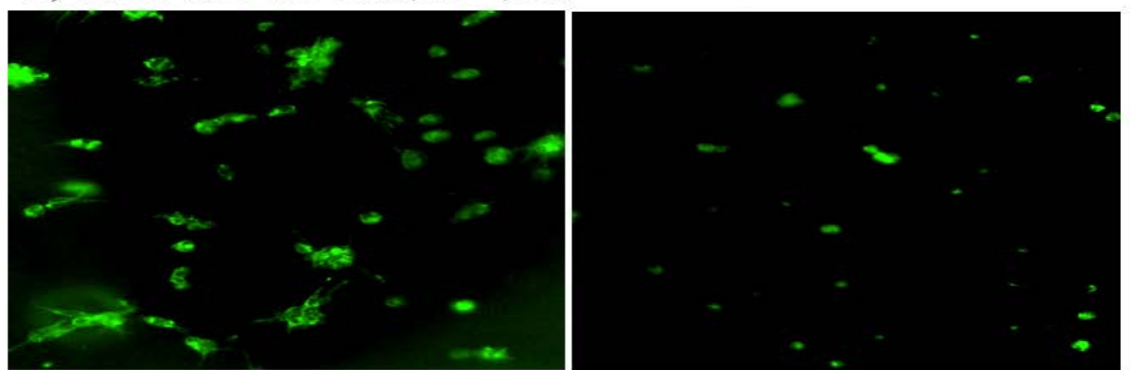

FITC

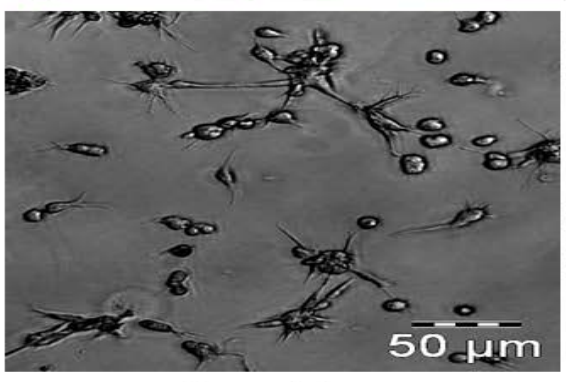

Parental

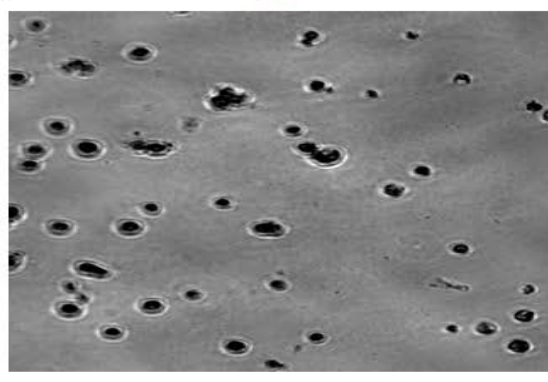

ShRNA-I
Phase

contrast

Figure 6: SHP2 inhibition suppresses invasion in BTBC cells: Representative phase images (lower panel) and fluorescence images (upper panel) showing impact of SHP2 inhibition on DQ 
collagen IV degradation in the MDA-MB-231 (A) and the MDA-MB 468 (B) cells. The micrographs were taken at the 24 hours time point.

\subsection{Loss of SHP2 decreases the level of matrix metalloproteinase 9 (MMP9) in conditioned} media

MMP9 and MMP2 are two members of the matrix metalloproteinase family that are expressed in human cancers and are thought to play critical role in tumor invasion and metastasis [5, 62]. Both MMPs have been implicated in the degradation of collagen IV, a major component of the basement membrane [62]. Hence, both are believed to contribute to the invasiveness of breast cancer cells. Previous reports presented evidence showing that SHP2 is required for the production and proteolytic activation of MMP2 and MMP9 in fibroblasts stimulated with Concanavalin A $[63,64]$. Moreover, SHP2 has also been shown to play a role in the increased level of MMP9 in the conditioned media of the MCF7 breast cancer cell line stimulated with IL$1 \mathrm{~B}[65]$.

Here, gelatin zymography was used to investigate whether SHP2 is involved in the regulation of MMP9 and MMP2 levels in the conditioned media of the MDA-MB-231 cells. Cells serumstarved overnight were stimulated with EGF (20 ng/ml) for 6 hours or left un-stimulated. Conditioned media was collected and assayed by gelatin zymography. Zymograms showed a reduction in the amount of degradation due to reduction at the level of MMP9 following SHP2 inhibition (Fig.7A and C). Band density measurements confirmed that SHP2 depletion resulted in an approximately 40\% reduction in MMP9 activity compared to the control (Fig.7B). Furthermore, EGF treatment resulted in an increase in MMP9 activity in control cells, whereas SHP2 depletion rendered cells non-responsive to EGF treatment (Fig.7B). Immunoblotting of the same conditioned media with anti-MMP9 antibody further confirmed a drastic reduction in 
MMP-9 levels as a result of SHP2 depletion (Fig.7C). Reprobing with an anti- $\beta$-actin antibody showed that contamination of the conditioned media with cell lysate was minimal (Fig.7C). To rule out the possibility that the observed difference in MMP9 level in the conditioned media was not due to variation in cell density, cell lysates prepared from same cultures were analyzed for total protein content and SHP2 expression. As shown in (Fig.7D), total protein levels were comparable in all lanes, and SHP2 expression was effectively silenced in the shRNA cells. These results indicate that SHP2 positively regulates MMP9 levels in conditioned media, but do not distinguish whether or not such role is a result of an effect on the secretion or expression of MMP9.

\section{A) Gelatin Zymography}

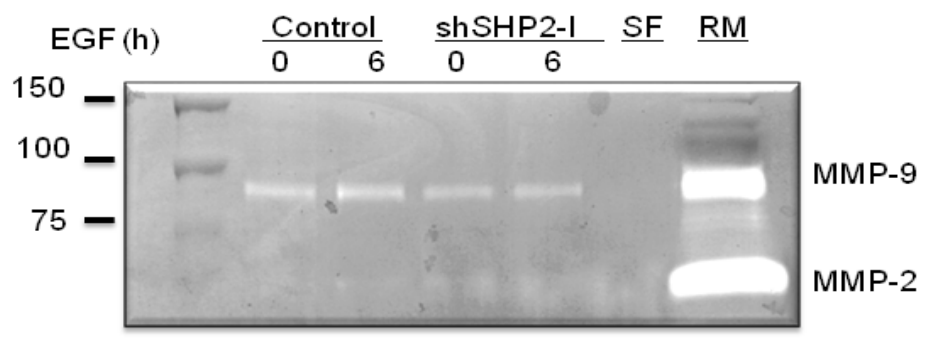

B) Band density

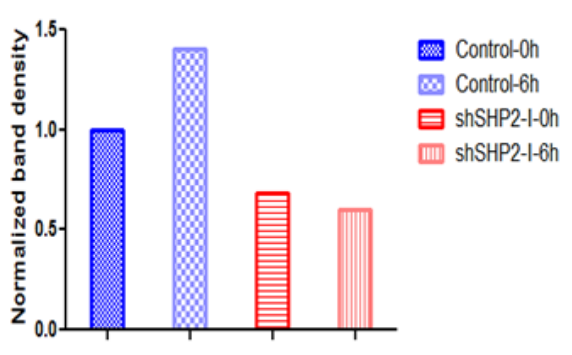

\section{C) Conditioned media}

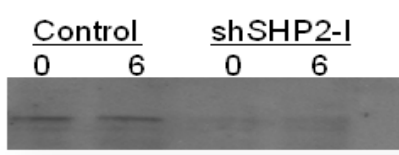

- B-actin

\section{D) Total cell lysates}

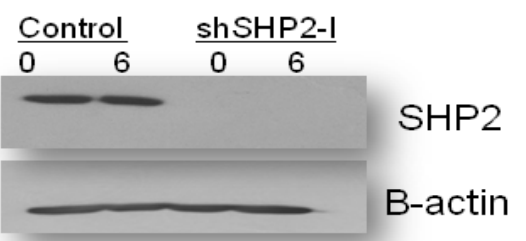

MDA-MB-231

Figure 7: SHP2 depletion decreased MMP9 level in condition media of MDA-MB-231: (A)

Gelatin zymography showing a reduction in MMP9-mediated degradation in the shRNA cells compared to controls. (B) Band density measurement of zymography. (C) Immunblotting 
analysis of conditioned media for MMP9 and $\beta$-actin. (D) Immunobotting analysis of total cell lysates for $\beta$-actin and SHP2.

\subsection{Depletion of SHP2 suppresses the tumorigenic potential of BTBC cells}

Very recent reports have demonstrated a functional role for SHP2 in tumor maintenance and progression using different cell lines, including breast cancer cell lines [41, 49]. Having observed that SHP2 plays a significant role in the transformation process of BTBC cells in vitro, we asked whether SHP2 is involved in the tumorigenesis process in vivo. To test this, we investigated the effect of SHP2 depletion on the tumor growth of both MDA-MB-231 and MDAMB-468 cells orthotopically transplanted into the mammary fat pads of female NOD/SCID mice approximately 8 weeks old at the time of injection. The tumor volume measurements showed that SHP2 depletion in the MDA-MB-468 cells resulted in a significant decrease in the xenograft tumor growth rate. While the control tumors reached $\sim 3500 \mathrm{~mm}^{3}$ in 7 weeks, the shSHP2-II tumors were $\sim 700 \mathrm{~mm}^{3}$ by the same period of time (Fig.8A). In other words, the control tumors grew $\sim 5$ times larger than the shSHP2 tumors. Furthermore, the tumor weights collected at the time of termination from mice injected with MDA-MB-468 cells showed that SHP2 depletion resulted in a drastic decrease in the mean tumor weight (Fig.8C). Although the growth rate of tumors formed by the MDA-MB-231 cells was very slow, reaching $\sim 60 \mathrm{~mm}^{3}$ for the controls in 8 weeks, the overall trend of SHP2 inhibition on tumor growth was similar to that observed in the MDA-MB468 cells (Fig.8B). These data provide evidence that SHP2 promotes the growth of BTBC tumors. 

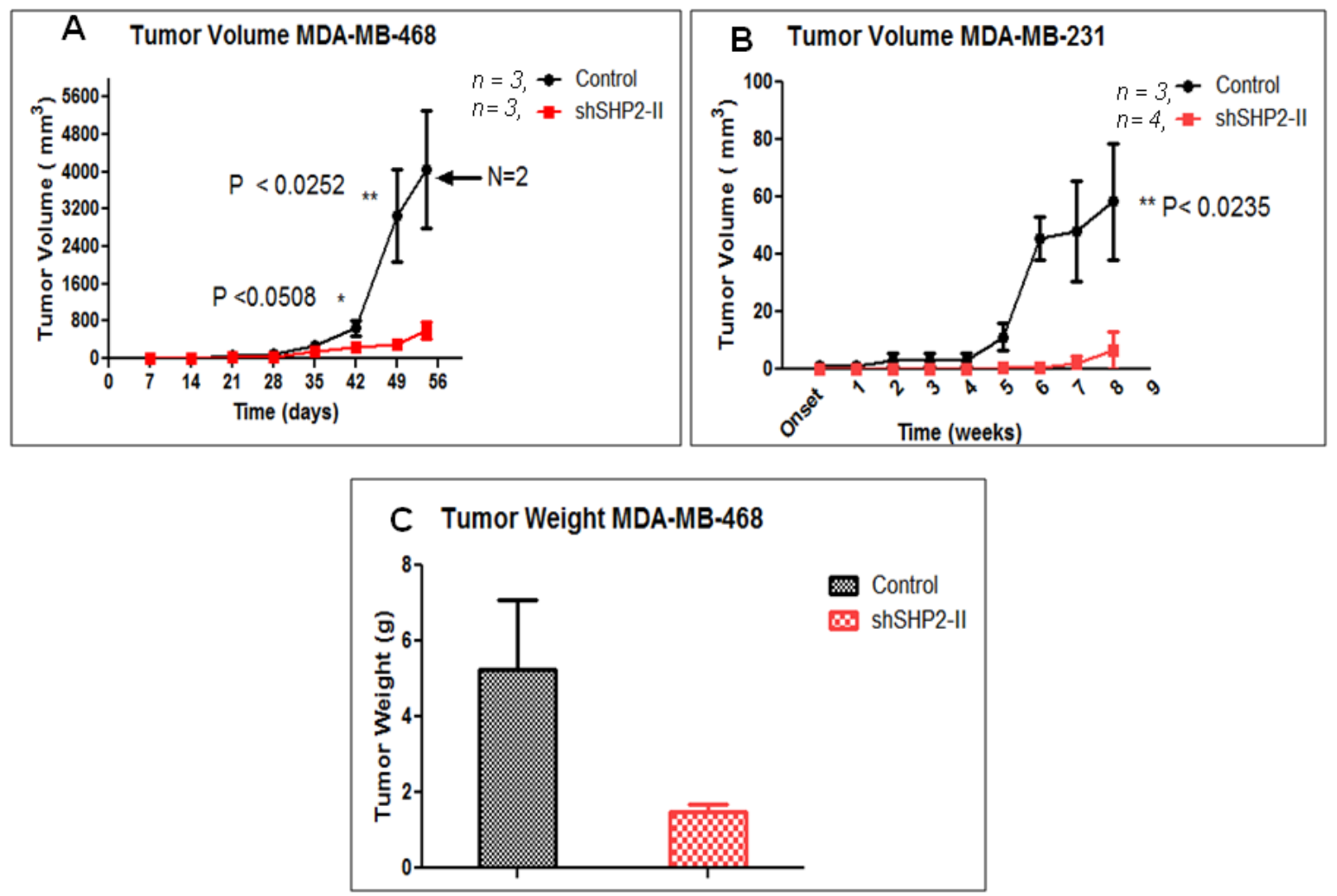

Figure 8: SHP2 promotes tumorigenesis of BTBC cells: Tumor growth rate was determined by measuring tumor volume as described in the materials and methods. Note that the control cells derived from the MDA-MB-468 (A) are highly tumorigenic and inhibition of SHP2 suppressed this potential significantly. On the other hand, cells derived from the MDA-MB-231 (B) were less tumorigenic, but the impact of SHP2 inhibition was similar. Data shown is mean \pm SEM of tumor volume. MDA-MB-468: Control $n=3$, shSHP2-II $n=3$; MDA-MB-231: Control $n=3$ and shSHP2-II $n=4$. (C) Bar graph showing mean tumor weight (g) \pm SEM for the MDA-MB-468 tumors. 


\subsection{Loss of SHP2 suppresses lung metastasis.}

To determine whether or not SHP2 is required for the metastatic potential of the BTBC tumors, lungs harvested from mice bearing the control- and shSHP2-II-expressing tumors were analyzed by histological evaluation following hematoxylin and eosin staining. Microscopic examination showed no metastasis in the lungs of both control and shSHP2-II mice that bore MDA-MB-468 tumors (data not shown), suggesting that these cell lines are highly tumorigenic, but not metastatic. On the other hand, the lungs from all of the control mice that had MDA-MB231-derived mammary tumors had massive metastasis (Fig.9). Surprisingly, the lungs of shSHP2-II mice had no observable metastatic cells suggesting that SHP2 is required not only for tumor growth, but also for metastasis of the MDA-MB-231 cells.

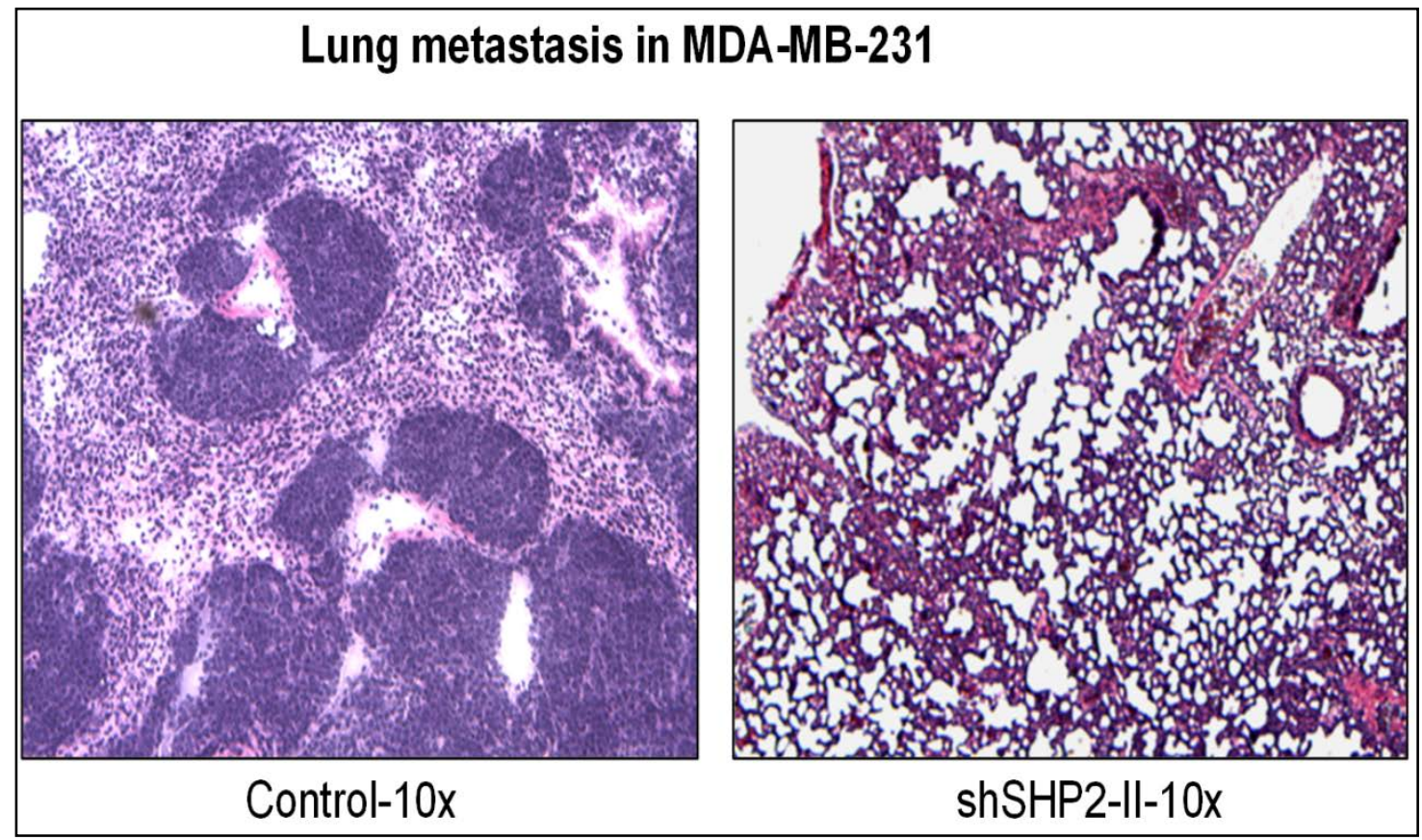

Figure 9: SHP2 inhibition abolishes the metastatic potential of the MDA-MB-231 cells. Representative H\&E stained sections of lungs from mice bearing MDA-MB-231-Control or 231shSHP2-II tumors are shown. Metastases were found in 3 out of 3 animals in the control group and none were found in animals bearing tumors expressing shSHP2-II. 


\subsection{SHP2 depletion decreases self-renewal of tumor initiating cells (TICs)}

Tumors, similar to normal tissues, are believed to be composed of cells with different differentiation states and variable capacity for self-renewal [66]. It has been shown that minority cell populations within a tumor have the capacity to self-renew, and as such, they are responsible for perpetual growth of a tumor [67]. Serial passaging experiments have demonstrated that only self renewing tumor cells have the capacity to initiate new tumors when transplanted into immune deficient mice [66]. These minority populations are referred to as tumor initiating cells (TICs) or cancer stem cells, multipotent tumor cells with the capacity to self-renew and to recapitulate the tumors they are derived from upon transplantation into immune-deficient mice [66]. TICs can be characterized by specific cell surface antigens such as CD44+/CD24-, accompanied by ALDH1 expression, and by the mammosphere assay, an in vitro assay that can also be used to enrich for the TICs that are able to grow as spheres in anchorageindependent, growth factor enriched, and serum-free conditions [68].

The observation from the soft agar assay where it took at least 3-4 weeks to see any difference in colony numbers between the SHP2-depleted cells compared to the control cells, as well as the drastic difference in xenograft tumor volume, led us to investigate the effect of SHP2 depletion in the self-renewal capacity of TICs using the mammosphere assay. We measured the mammosphere formation efficiency of BTBC cell lines in the presence or upon SHP2 depletion. To assess whether SHP2 influences the self-renewal of TICs, we dissociated the primary mammospheres into single cells and reseeded them. As shown in (Fig.10A), SHP2 depletion resulted in a significant decrease in the ability of both MDA-MB-231 and MDA-MB-468 cells to form mammospheres. Interestingly, the ratio of secondary to primary mammospheres was lower in shSHP2 cells than in the control cells, showing that SHP2 depletion decreases the self renewal 
capacity of TICs (Fig.10B). Thus, SHP2 is required for the self-renewal capacity of TICs in BTBC cells.

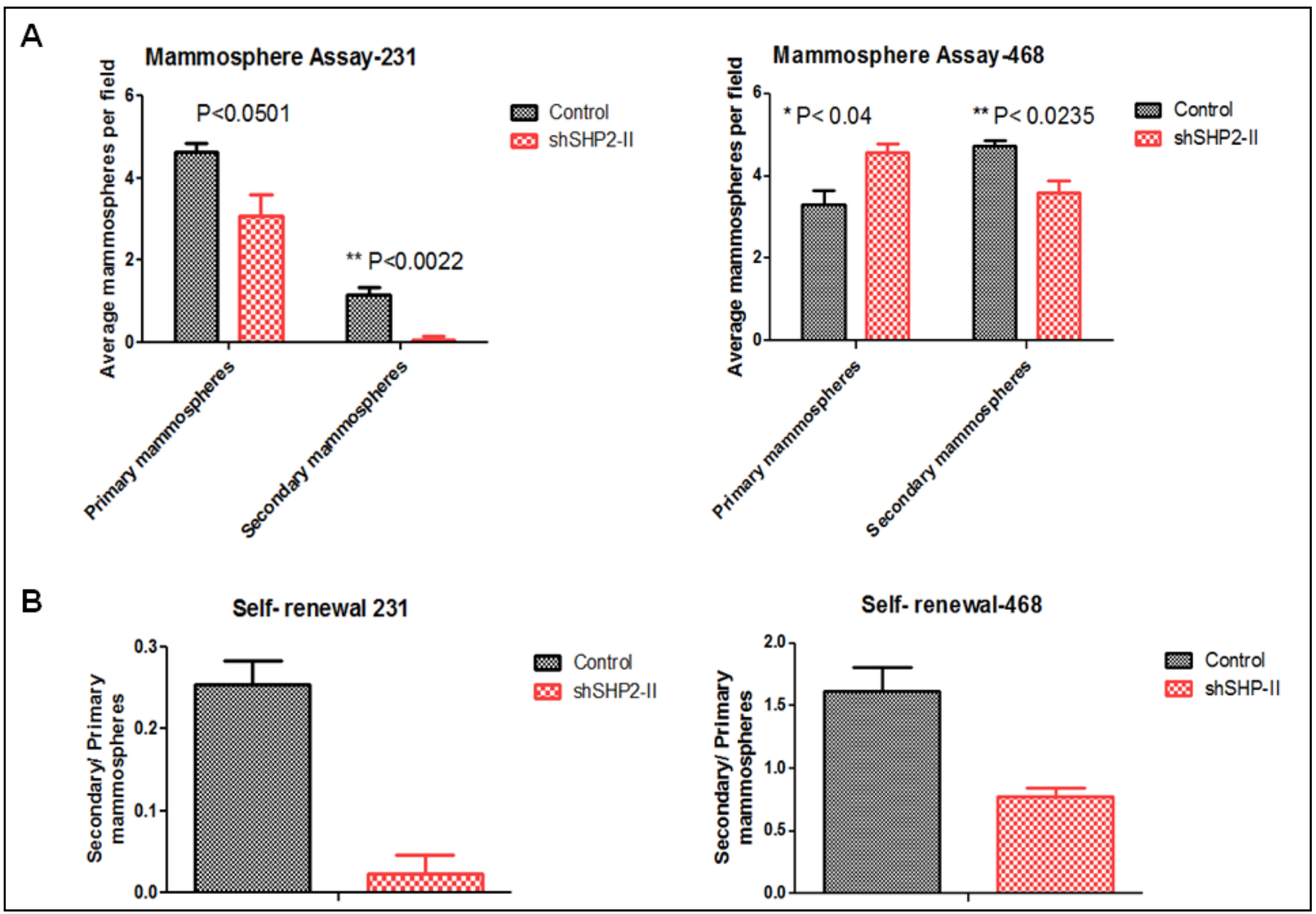

Figure 10: SHP2 knockdown decreases TICs self-renewal. Mean mammospheres formation (A) and self-renewal capacities (B) of MDA-MB-231 and MDA-MB-468 cells in the presence or upon SHP2 depletion. Self-renewal was reduced in the absence of SHP2. Results were represented as means \pm SEM of the triplicates. 


\subsection{SHP2 in BTBC cells signaling.}

\subsubsection{SHP2 is important for EGF-induced Ras activation}

SHP2 has emerged as a major regulator of the Ras/MAPK pathway downstream of receptor tyrosine kinases (RTK), especially pathways activated by EGFR [34]. To define the signaling pathways in BTBC cells that rely on SHP2 action, the state of Ras activation was determined in the MDA-MB-468 control- and shSHP2-expressing cells using the Ras binding domain of Raf-1 fused to GST (GST-RBD) as a reagent [22]. Because SHP2 is known to be required for increasing the intensity and duration of signaling induced by ligand-activated RTKs, these experiments were conducted in time-course manner by stimulating cells with EGF for varying time points. As shown in (Fig.11A), EGF-induced Ras activation was sustained for about 4 hours in control cells, whereas it was short-lived in the shSHP2 cells. Band density measurements from two different experiments further confirm this observation (Fig.11B). Immunoblotting of total cell lysates showed that the amount of total Ras level was comparable in all lanes, and the state of SHP2 depletion in the shSHP2 cells was efficient (Fig.11A). These results show that SHP2 is required for sustained Ras activation in MDA-MB-468 cells. 


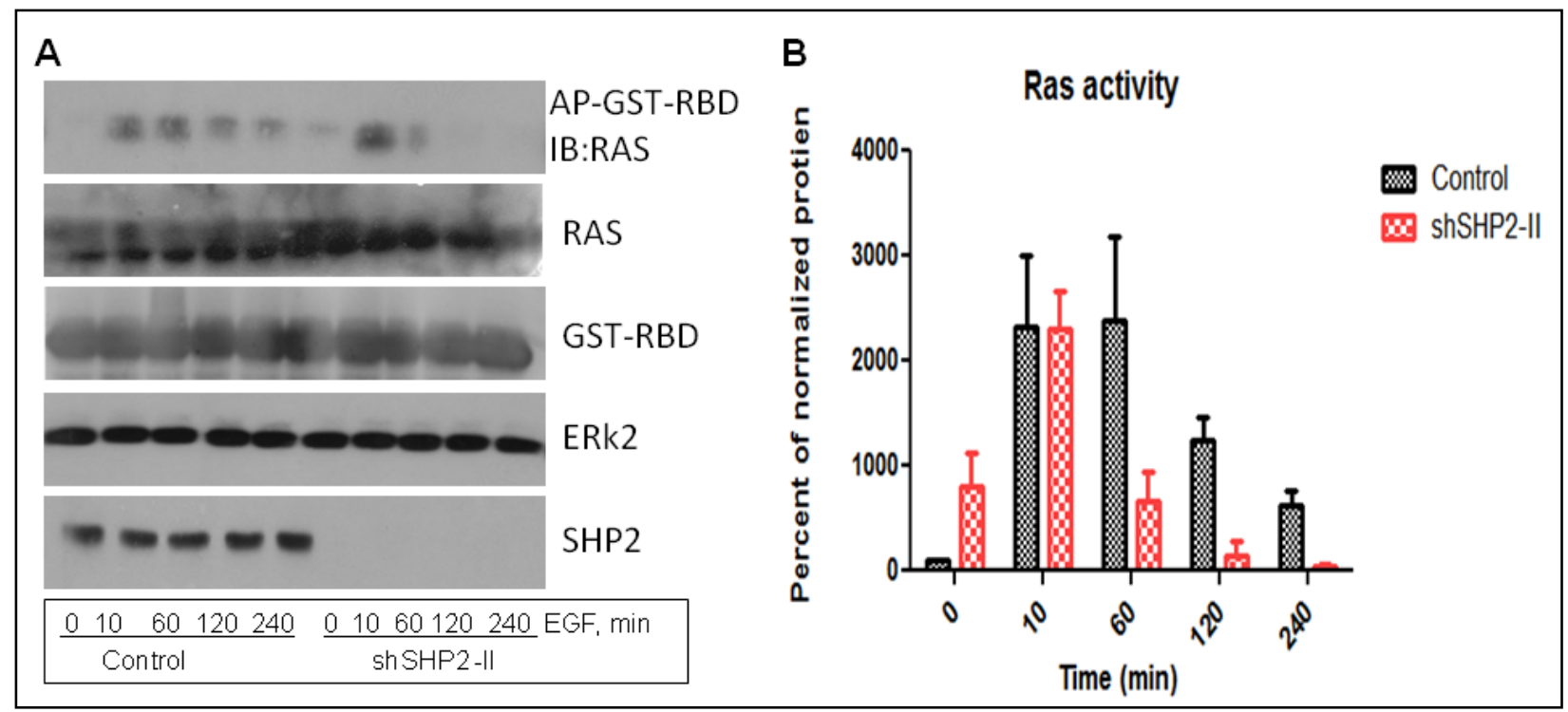

Figure 11: SHP2 is required for sustained Ras activation in MDA-MB-468: (A) MDA-MB468 cells were serum starved and stimulated with EGF (20 ng/ml) as indicated. Cell lysates were analyzed by immunoblotting with antibodies for Ras, GST, ERK2, and SHP2. (B) The bar graph showing SHP2 knockdown resulted in a short-lived Ras activation. 


\subsubsection{SHP2 modulates $\beta$-catenin and downstream signaling}

Recently, SHP2 has been implicated in modulating Wnt signaling. One of the suggested SHP2 substrates that mediates the effect in Wnt signaling is parafibromin/Cdc73 [39]. Other reports have also shown SHP2 modulating c-Myc and p27 protein levels in prostate, lung and breast cancer cell lines [41, 49].

The possibility of SHP2 modulates the Wnt- $\beta$-catenin signaling pathway in BTBC cells was explored. First, the level of $\beta$-catenin in the control and shSHP2 cells derived from the MDAMB-468 cells was examined by immunoblotting of total cell lysates. As shown in (Fig.12A), depletion of SHP2 resulted in a decreased level of $\beta$-catenin. Further, reprobing for the cell cycle regulator protein $\mathrm{p} 27$, a known transcriptional target of $\beta$-catenin, showed an increase in shSHP2 cells, which may explain the observed suppression of cell proliferation (see Fig. 12A) upon SHP2 depletion. Immunoblotting with anti- $\beta$-actin and anti-SHP2 antibodies showed comparable loading and efficient silencing, respectively. The band density measurements further confirmed impact of SHP2 depletion on $\beta$-catenin, and p27 (Fig.12B).

Furthermore, immunoblotting of tumor lysates collected from MDA-MB-468 xenograft cells confirmed persistent reduction in $\beta$-catenin levels in SHP2 depleted tumors. Altogether, these results suggest that SHP2 may promote the tumorigenic potential of BTBC cells through modulation of $\beta$-catenin levels. 

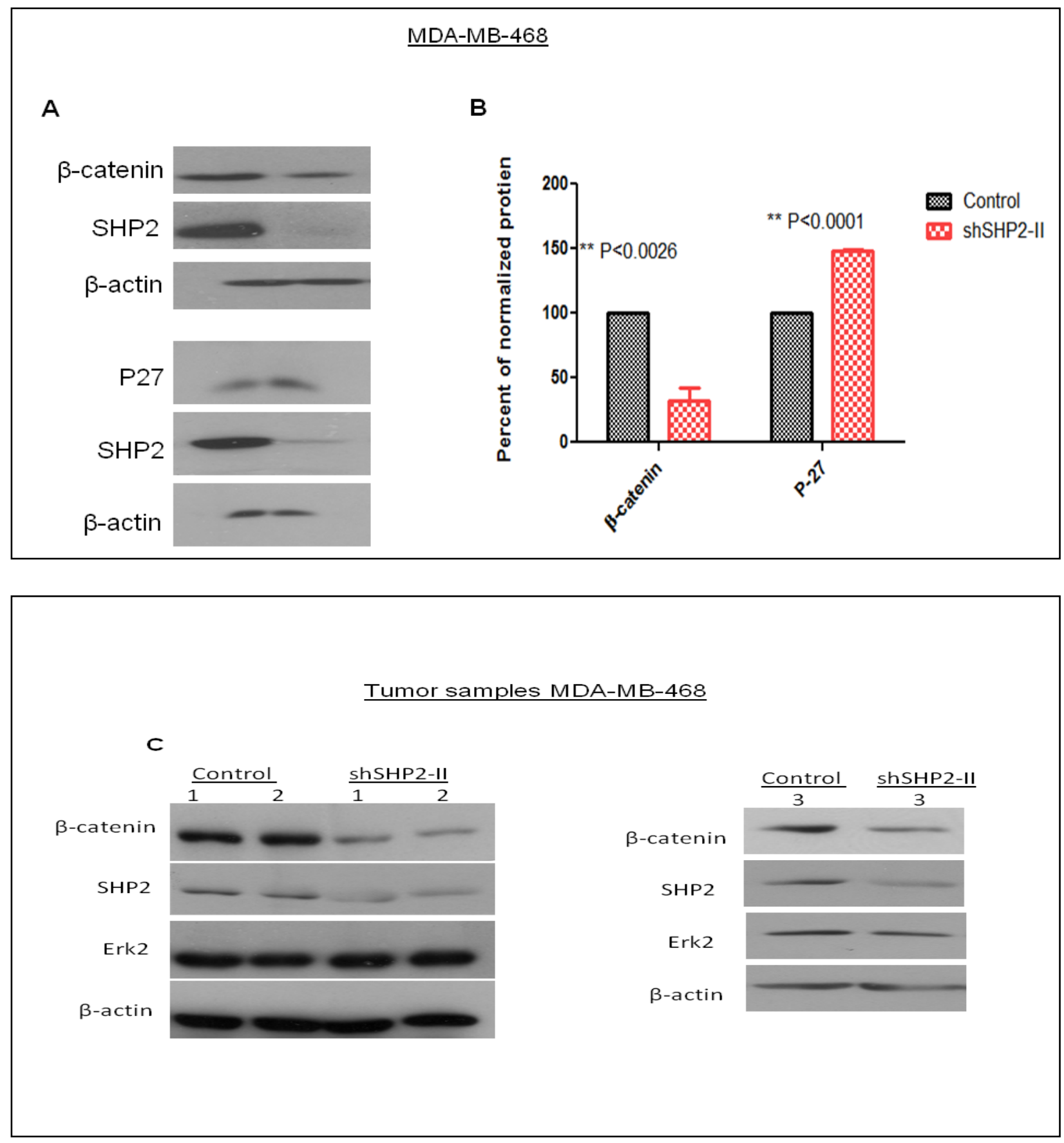

Figure 12: SHP2 modulates $\beta$-catenin, and p-27 protein levels in the MDA-MB-468 cells. (A) Immunoblotting analysis of control and shSHP2 lysates for the indicated proteins. (B) The bar graph showing SHP2 depletion leading to reduction in $\beta$-catenin and an increase in p27 levels. (C) Immunoblotting analysis of tumor lysates derived from 3 controls and 3 shSHP2 mice for the indicated proteins. 


\section{DISCUSSION}




\subsection{SHP2 as a potential target in BTBC}

Breast cancer continues to be a major health problem effecting women worldwide. Of particular concern is BTBC that is associated with poor prognosis and does not respond to standard targeted therapies. Still, no effective targeted therapy has been identified to date for this subtype; and there is a great need for identifying signaling proteins that play critical roles in the development of BTBC. Overexpression of EGFR often occurs in BTBC cell lines and tumors [15]. In addition, phosphorylation of EGFR has been found to be higher in BTBC than the luminal subtype, suggesting more active pathway [69]. Furthermore, the RAS/MAPK and the Wnt/ $\beta$-catenin pathways are activated and highly involved in tumor progression of BTBC [70,

71]. SHP2 is well-known to positively modulate these pathways, especially the one elicited by EGFR. It is unknown, however, to what extent SHP2 is involved in the development and signaling of BTBC. Therefore, it was of interest to investigate whether SHP2 plays a role in the tumorigenesis of BTBC. To study this possibility, we generated two different anti-SHP2 shRNAs that have been previously reported to successfully silence SHP2 [72]. Then, the antiSHP2 shRNAs were used interchangeably to assess the effects of SHP2 depletion on BTBC cell proliferation, transformation, migration, invasion and xenograft growth. Finally, we dissected the roles of SHP2 in EGF-induced Ras activation and in Wnt/ $\beta$-catenin signaling.

\subsection{SHP2 knockdown results in decreased cell proliferation}

As a first step to study SHP2 role in the tumorigenesis of BTBC cells, we sought to investigate the effect of SHP2 knockdown on cell proliferation. Using the EdU assay we found that SHP2 depletion resulted in a 37\% decrease in cell proliferation of MDA-MB-231 cells (Fig.3B). These results were consistent with previous reports showing that SHP2 is important 
for cell proliferation of normal and cancer cell lines [24, 41, 73, 74]. For example, one of the first lines of evidence linking SHP2 to cell proliferation came from the observation that insulininduced cell proliferation of the 3T3 cells was suppressed by the ectopic expression of mutant $\mathrm{SHP}^{\mathrm{CS}}$ form $[24,33]$. Similar results were obtained in mouse fibroblast expressing mutant SHP2 upon treatment with EGF and PDGF [74]. Furthermore, SHP2 has been shown to be a critical mediator of cell growth and transformation of 3T3 cells expressing the constitutively active form of fibroblast growth factor receptor-3 (FGFR-3) [75]. While others have shown that SHP2 promote cell proliferation of prostate and lung cancer cell lines [41]. Taken together, these findings suggest that SHP2 promotes tumorigenesis at least partly by promoting cell proliferation.

\subsection{Inhibition of SHP2 suppresses cell transformation}

One important hallmark of cancer cells is their ability to grow in an anchorage-independent manner. Therefore, a soft agar assay is routinely used to determine the impact of gene manipulation or drug treatment on cancer cell transformation. Here, we demonstrated that SHP2 inhibition suppressed BTBC cell transformation, as evidenced by the loss of anchorageindependent growth (Fig.4 (A-D)). These findings are consistent with the reports indicating that SHP2 is required for cell transformation induced by the constitutively active form of FGFR-3 and v-Src $[75,76]$. They are also in agreement with a previous report implicating a role for SHP2 in the transformation phenotype of various breast cancer cell lines [48]. Collectively, these observations confirm that SHP2 plays a significant role in the transformation process in vitro and suggests a role for the enzyme in tumorigenesis in vivo. 


\subsection{Depletion of SHP2 suppresses BTBC wound healing in vitro}

The wound healing assay is one of the earliest methods that have been developed to monitor cell behaviors, including cell migration and proliferation [77]. Using the wound healing assay, we found that depletion of SHP2 suppressed the ability of BTBC cells to fill wounded regions (Fig. 5(A and $\mathrm{B})$ ). Our findings were consistent with a previous report implicating a role for SHP2 in the wound healing process of breast cancer cell lines [48]. Furthermore, a modified chamber assay demonstrated that fibroblast cells lacking a functional SHP2 have impaired migration and spreading associated with increased focal adhesions [60, 61]. Collectively, these observations confirm a role for SHP2 in the wound healing process in BTBC and suggest that SHP2 regulates cell migration and probably metastasis of BTBC cells.

\subsection{SHP2 knockdown results in decreased cell invasion}

Elucidating the signaling molecules that play role in invasion could provide a mechanistic understanding of the invasion process [78]. Here, using a 3D assay which more accurately reflects the tumor microenvironment, we demonstrated that SHP2 inhibition suppressed BTBC cell invasion, as evidenced by the loss of ability to degrade DQ-collagen embedded in Matrigel (Fig.5 (A and B)). Interestingly, SHP2 has been shown to regulate the activity of the signaling molecules that are involved in invasion such as Fyn and p190RhoGap [78]. For example, SHP2 recruitment and activation with subsequent Fyn activation is essential for the $\alpha 6 \beta 4$ integrin to optimally promote invasion in breast cancer cell lines [78]. Moreover, recent report has shown that SHP2 is fundamental to breast cancer invasion ex vivo and in vivo [49]. 
In agreement with previous reports our observations confirm that SHP2 plays a significant role in the invasion process in vitro, and suggests that targeting SHP2 in BTBC may be useful for blocking this crucial cancer hallmark.

\subsection{SHP2 depletion decreases MMP9 levels in conditioned media}

The previous observation pointing at an important role for SHP2 in cancer cell invasion using the 3D assay, have led us to investigate whether SHP2 affects the production of matrix metalloproteinase. For example, MMP9 and MMP2 have been implicated in the degradation of collagen IV a major component of the basement membrane [64]. Degradation of basement membrane is considered the first crucial step in tumor cell invasion, and cancer cells must be able to mobilize and produce matrix metalloproteinases to be able to breach this barrier [62]. Increased expression of MMP2 and MMP9 has been observed in breast tumors in both stromal and cancer cells [79]. Moreover, it has been shown that stimulation of the cell with growth factors, cytokines, and lectins such as concanavalin A (ConA) further promotes the secretion of MMP9 [62-64, 79].

In this study we found that depletion of SHP2 in MDA-MB-231 resulted in a drastic decrease in MMP9 level in the conditioned media (Fig.7B). The results demonstrated that the enzyme was in the latent form, as reflected by its molecular mass of $92 \mathrm{kDa}$, and not in the active form (82 kDa) (Fig.7A). Furthermore, EGF induced the secretion of MMP9 in the control cells; however, depletion of SHP2 rendered the cell nonresponsive to EGF stimulation (Fig.7A). Whether the decreased level of MMP9 in the conditioned media was due to increased protein expression or secretion was not investigated. 
Previous work in fibroblasts cells expressing mutant SHP2 has implicated the phosphatase in the production and secretion of MMP2 and MMP9 upon stimulation with Con A [63, 64]. Furthermore, using MCF-7 cells SHP2 has been shown to regulate secretion of MMP9 upon stimulation with IL-1B [65]. Thus, SHP2 appears to regulate MMP9 activity in both normal and malignant cells. Our results indicate the effect of SHP2 on MMP9 was specific, since MMP2 was not affected by SHP2 depletion or EGF stimulation in these cells (data not shown). This is consistent with the difference in the transcriptional regulation of MMP2 and MMP9, since different response elements are present in their promoter regions [79]. However, unlike the previous report in the normal fibroblasts, we did not see any difference in MMP2 level in the conditioned media upon SHP2 inhibition in MDA-MB-231 cells.

In conclusion, our results suggest that SHP2 may modulate invasion of metastatic breast cancer cells in part by increasing the secretion/expression of MMP9.

\subsection{SHP2 knockdown suppresses BTBC xenograft tumor growth and lung metastasis}

The findings that SHP2 depletion suppressed BTBC cell proliferation and transformation in vitro raised the possibility that SHP2 is also required for tumorigenesis in vivo. Here, we provided evidence showing that SHP2 is indeed required for tumor maintenance and progression of BTBC in vivo (Fig.8A-C). Furthermore, using metastatic cell lines such as MDA-MB-231, we demonstrated that SHP2 depletion abolished lung metastasis (Fig.9). These results were consistent with recent reports implicating SHP2 in tumor growth in vivo using different cell types $[41,49]$. Altogether, these findings reveal an important role for SHP2 in tumor growth of BTBC and establish an important role for SHP2 in tumorigenesis in vivo. 


\subsection{Inhibition of SHP2 suppresses the self-renewal capacity of TICs}

Previous observations pointing at the role for SHP2 in the transformation and tumorigenesis of BTBC, have led us to investigate the effect of SHP2 depletion on the self-renewal capacity of the TICs. The mammosphere assay was used to assess this possibility. First, we demonstrated that SHP2 depletion resulted in a significant decrease in the mammosphere numbers (Fig.10A). Second, we showed that SHP2 depletion suppressed the self-renewal capacity of the TICs (Fig.10B). Our findings were consistent with the previous report showing that SHP2 influence the self-renewal capacity of TICs in HER2- positive and triple negative breast cancer cell lines [49]. Collectively, these findings confirm that SHP2 promote the self-renewal capacity of TICs in breast cancer cell lines.

\subsection{SHP2 signaling in BTBC cells}

\subsubsection{SHP2 regulates EGF-induced Ras activation in BTBC cells}

Genetic Ras mutation is infrequent in breast cancer; however, the Ras signaling pathway gets abnormally activated in tumors overexpressing growth factor receptors such as EGFR and HER2 [71]. Specifically, BTBC tumors tend to overexpress EGFR. Since SHP2 is a major regulator of the Ras/MAPK pathway downstream of RTKs, we hypothesized that the regulation of tumorigenesis was mediated through the control of this particular pathway. We found that SHP2 is required for sustained EGF-stimulated Ras activation in MDA-MB-468 (Fig.11A). Therefore, it is likely that SHP2 mediates part of its effect on tumorigenesis of BTBC through the regulation of EGF-induced Ras activation. 


\subsubsection{SHP2 regulate the Wnt/ $\beta$-catenin signaling in BTBC cells}

The Wnt/ $\beta$-catenin pathway is a major regulator of cellular processes including cell proliferation, migration, and differentiation. This makes it one of the significant pathways that are implicated in embryonic development and tumorigenesis [80]. Upon Wnt activation $\beta$ catenin is translocated from the membrane to the nucleus where it interacts with transcriptional activators to modulate the expression of target genes such as c-myc, CD1, or p27 genes associated with increased cell growth, invasion, and transformation [70, 81]. Several reports have shown that the Wnt/ $\beta$-catenin signaling pathway is activated in basal type and triple negative breast cancer, and this activation is associated with poor outcome [70, 82].

Here, we found that one of the mechanisms through which SHP2 exerts its effects on tumorigenesis requires the Wnt/ $\beta$-catenin pathway. We demonstrated that SHP2 knockdown in MDA-MB-468 cells resulted in depletion of $\beta$-catenin protein levels, which resulted in an increase in p27 protein levels. These findings uncover a previously unknown mechanism of $\beta$ catenin regulation by SHP2 and identify a SHP2-dependent signaling role that enhances the maintenance and progression of BTBC xenografts. Finally, to assess the generality of this mechanistic finding, we analyzed the effect of SHP2 depletion on $\beta$-catenin levels in two different cell lines, MDA-MB-231 and BT20 (data not shown). Unfortunately, SHP2 inhibition did not affect $\beta$-catenin in these cell lines, suggesting that the mechanism we provided here could be cell specific for MDA-MB-468 cells. 


\subsection{Study limitations and future directions}

The protein tyrosine phosphatase SHP2 can act at multiple signaling sites simultaneously to regulate multiple cellular processes including cell growth, survival, motility, and apoptosis [29]. We have demonstrated an effect for SHP2 in cell proliferation under cell culture; however we did not investigate the effects of SHP2 on other cellular processes in this study in vivo. It would be of interest to investigate the role of SHP2 in BTBC cellular pathways in vivo. For example, we can investigate apoptosis by staining the frozen xenograft tumor sections with caspase 3 , a marker of induced apoptosis.

Angiogenesis is one of the rate limiting steps in tumor progression in vivo. Inadequate blood supply will impair the ability of the tumor to proliferate and metastasize to other sites. Therefore, it would be of interest to stain the frozen xenograft tumor sections with CD31, a marker for blood vessel enrichment in the tumor sections. For a definitive assessment of the role of SHP2 in cell proliferation in vivo, it would be of interest to stain the frozen tumor sections with the proliferation marker Ki67.

Although we could show that SHP2 knockdown in MDA-MB-468 resulted in depletion of $\beta$ catenin, we did not investigate whether this was a result of SHP2 depletion and not an off-target effect of the shRNAs used to target SHP2. The fact that we generated two different anti-SHP2 shRNAs that gave the same results indicates specificity toward SHP2 and excludes any off-target effect. However, it would be of interest to rescue SHP2 expression, and investigate whether it will also rescue $\beta$-catenin level. Afterwards, we can investigate the mechanism into how SHP2 depletion results in decreased $\beta$-catenin level in MDA-MB-468 cells.

Stable knockdown of SHP2 resulted in an effective suppression of tumor growth in vivo and abolished lung metastasis. However, effect on metastasis could actually result from SHP2 
depletion affecting cell proliferation and decreasing tumor burden rather than a direct effect on metastasis. Therefore, for a more accurate representation of the effects of SHP2 depletion on metastasis in vivo, it would be of interest to use an inducible system because SHP2 tumor burden would be in place at the time of SHP2 knockdown.

We demonstrated an effect for SHP2 knockdown on MMP9 protein level in conditioned medium. However, the results that we provided cannot distinguish whether the effect of SHP2 depletion was a result of an effect on secretion or production of MMP9 in MDA-MB-231 cells. To answer this question, it would be of interest to investigate MMP9 mRNA and protein expression in whole cell lysate under condition of SHP2 knockdown. 


\section{SUMMARY AND CONCLUSION}


Tyrosine phosphorylation is an important signaling event that regulates several cellular processes such as cell growth, survival, migration, differentiation and apoptosis [25]. Aberrant regulation of tyrosine phosphorylation is linked to the development of cancer and other human diseases [28]. Several experimental studies demonstrate that altered expression or mutations in protein tyrosine kinases (PTKs) are linked to the development of many forms of human cancer [42]. However, our knowledge on the role of protein tyrosine phosphatases (PTPs) in cancer pathogenesis lags behind our understanding of kinases. Relatively, little is known about the role of some PTPs contributing to cancer pathogenesis and progression, especially regarding the connection of SHP2 with solid tumor progression. In this study we investigated the role of the protein tyrosine phosphatase SHP2 in the tumorigenesis of BTBC in vivo. BTBC represents the most challenging subtype of breast cancer to treat, and new therapeutic targets are urgently needed.

Here, we demonstrated that SHP2 knockdown resulted in decreased cell proliferation, transformation, migration and invasion of BTBC cells. More importantly, we showed that SHP2 is required for BTBC xenograft tumor maintenance and progression, and its depletion abolished lung metastasis. In exploring the molecular mechanism by which SHP2 mediates its effects, we demonstrated that SHP2 is required for sustained EGF-induced Ras activation in MDA-MB-468 cells. Furthermore, we discovered that SHP2 regulates the Wnt/ $\beta$-catenin signaling pathway in MDA-MB-468 cells. In addition, we demonstrated a role for SHP2 in the propagation and the self-renewal capacity of TICs. In conclusion, these findings suggest SHP2 plays an essential role in BTBC development and reinforce the concept of developing a specific inhibitor targeting SHP2 in BTBC. 
6. CURRICULUM VITAE 
PERSONAL AND CONTACT INFORMATION

Name: $\quad$ Fatimah Matalkah

Date of Birth: $\quad$ May 31, 1978

Place of Birth: $\quad$ Irbid, Jordan

Marital Status: Married

E-mail Address: fatimah_kh@yahoo.com

EDUCATION

December, 2005

M.Sc. in Environmental Engineering, Colorado University at Boulder, Colorado, USA.

June, 2000

B.Sc. in Applied Biology: sub-specialization in Microbiology. Jordan University of Science and Technology (JUST), Irbid, Jordan

TRAINING \& INTERNSHIP

May-August, 1999

Summer Training at the Laboratories of Infectious Diseases. Badeah Hosipital, Irbid, Jordan.

AWARDS AND HONORS

June, 2000

Ranked first among the 109 students at Jordan University of Science and Technology Department of Applied Biology. 


\section{PUBLICATION}

Kujundzic, E., Matalkah, F., Howard , H., Hernandez , H., and Miller, S. 2006: UV Air Cleaners and Upper-Room Air Ultraviolet Germicidal Irradiation for Controlling Airborne Bacteria and Fungal Spores. Journal of Occupational and Environmental Hygiene. 3(10): 53646.

\section{POSTERS}

Fatimah Matalkah and Yehenew Agazie: SHP2 as a Potential Therapeutic Target in BTBC. Van Liere Research Convocation. March 9, 2012. 


\section{REFERENCES}


1. Grizzi, F., et al., Cancer initiation and progression: an unsimplifiable complexity. Theor Biol Med Model, 2006. 3: p. 37.

2. Ramaswamy, S., Translating Cancer Genomics into Clinical Oncology. New England Journal of Medicine, 2004. 350(18): p. 1814-1816.

3. Chin, L., et al., Making sense of cancer genomic data. Genes Dev, 2011. 25(6): p. 53455.

4. Jones, P.A. and S.B. Baylin, The epigenomics of cancer. Cell, 2007. 128(4): p. 683-92.

5. Hanahan, D. and R.A. Weinberg, The Hallmarks of Cancer. Cell, 2000. 100(1): p. 57-70.

6. Hanahan, D. and Robert A. Weinberg, Hallmarks of Cancer: The Next Generation. Cell, 2011. 144(5): p. 646-674.

7. American Cancer Society. Breast Cancer Facts \& Figures 2011-2012. Available at: http://www.cancer.org/acs/groups/content/@epidemiologysurveilance/documents/docum ent/acspc-030975.pdf.

8. Society, A.C., Cancer Facts \& Figures 2012, in Atlanta. 2012.

9. Hahn, W.C. and R.A. Weinberg, Rules for making human tumor cells. N Engl J Med, 2002. 347(20): p. 1593-603.

10. Polyak, K. and P.K. Vogt, Progress in breast cancer research. Proceedings of the National Academy of Sciences, 2012. 109(8): p. 2715-2717.

11. Youlden, D.R., et al., The descriptive epidemiology of female breast cancer: an international comparison of screening, incidence, survival and mortality. Cancer Epidemiol, (2012 Mar 27): p. 2012 Jun;36(3):237-48.

12. Bertucci, F., P. Finetti, and D. Birnbaum, Basal Breast Cancer: A Complex and Deadly 
Molecular Subtype. Current Molecular Medicine, 2012. 12(1): p. 96-110.

13. Al-Hajj, M., et al., Prospective identification of tumorigenic breast cancer cells. Proceedings of the National Academy of Sciences, 2003. 100(7): p. 3983-3988.

14. Cleator, S., W. Heller, and R.C. Coombes, Triple-negative breast cancer: therapeutic options. The Lancet Oncology, 2007. 8(3): p. 235-244.

15. Duffy, M.J., P.M. McGowan, and J. Crown, Targeted therapy for triple-negative breast cancer: where are we? International Journal of Cancer, 2012: p. 'Accepted Article’, doi: 10.1002/ijc.27632.

16. Perou, C.M., et al., Molecular portraits of human breast tumours. Nature, 2000. 406(6797): p. 747-752.

17. Sørlie, T., et al., Gene Expression Patterns of Breast Carcinomas Distinguish Tumor Subclasses with Clinical Implications. Proceedings of the National Academy of Sciences of the United States of America, 2001. 98(19): p. 10869-10874.

18. Pal, S., B. Childs, and M. Pegram, Triple negative breast cancer: unmet medical needs. Breast Cancer Research and Treatment, 2011. 125(3): p. 627-636.

19. Valentin, M., et al., Molecular insights on basal-like breast cancer. Breast Cancer Research and Treatment: p. 1-10.

20. Rakha, E.A., et al., Triple-negative breast cancer: distinguishing between basal and nonbasal subtypes. Clin Cancer Res, (2009 Mar 24): p. 2009 Apr 1;15(7):2302-10.

21. Beate C. Litzenburger, et al., High IGF-IR Activity in Triple-Negative Breast Cancer Cell Lines and Tumorgrafts Correlates with Sensitivity to Anti-IGF-IR Therapy

Clin Cancer Res 2011. 17: p. 2314-2327.

22. Agazie, Y.M. and M.J. Hayman, Molecular mechanism for a role of SHP2 in epidermal 
growth factor receptor signaling. Mol Cell Biol, 2003. 23(21): p. 7875-86.

23. Feng, G.-S., Shp-2 Tyrosine Phosphatase: Signaling One Cell or Many. Experimental Cell Research, 1999. 253(1): p. 47-54.

24. Lai, L., et al., The Shp-2 tyrosine phosphatase

Protein Phosphatases, J. Ariño and D. Alexander, Editors. 2004, Springer Berlin / Heidelberg. p. 275-299.

25. Neel, B.G., H. Gu, and L. Pao, The 'Shp'ing news: SH2 domain-containing tyrosine phosphatases in cell signaling. Trends Biochem Sci, 2003. 28(6): p. 284-93.

26. Hof, P., et al., Crystal Structure of the Tyrosine Phosphatase SHP-2. Cell, 1998. 92(4): p. 441-450.

27. Dance, M., et al., The molecular functions of Shp2 in the Ras/Mitogen-activated protein kinase (ERK1/2) pathway. Cellular Signalling, 2008. 20(3): p. 453-459.

28. Mohi, M.G. and B.G. Neel, The role of Shp2 (PTPN11) in cancer. Current Opinion in Genetics and Development, 2007. 17(1): p. 23-30.

29. Qu, C.-K., Role of the SHP-2 tyrosine phosphatase in cytokine-induced signaling and cellular response. Biochimica et Biophysica Acta (BBA) - Molecular Cell Research, 2002. 1592(3): p. 297-301.

30. Grossmann, K.S., et al., Chapter 2 - The Tyrosine Phosphatase Shp2 in Development and Cancer, in Advances in Cancer Research, F.V.W. George and K. George, Editors. 2010, Academic Press. p. 53-89.

31. Tang, T.L., et al., The SH2-containing protein-tyrosine phosphatase SH-PTP2 is required upstream of MAP kinase for early xenopus development. Cell, 1995. 80(3): p. 473-483.

32. Feng, G.S., Shp2-mediated molecular signaling in control of embryonic stem cell self- 
renewal and differentiation. Cell Res, 2007. 17(1): p. 37-41.

33. Milarski, K.L. and A.R. Saltiel, Expression of catalytically inactive Syp phosphatase in $3 T 3$ cells blocks stimulation of mitogen-activated protein kinase by insulin. J Biol Chem, 1994. 269(33): p. 21239-43.

34. Agazie, Y.M. and M.J. Hayman, Molecular mechanism for a role of SHP2 in epidermal growth factor receptor signaling. Molecular and cellular biology, 2003. 23(21): p. 787586.

35. Wu, C.J., et al., The tyrosine phosphatase SHP-2 is required for mediating phosphatidylinositol 3-kinase/Akt activation by growth factors. Oncogene, 2001. 20(42): p. 6018-25.

36. Zhang, S.Q., et al., Receptor-specific regulation of phosphatidylinositol 3'-kinase activation by the protein tyrosine phosphatase Shp2. Molecular and cellular biology, 2002. 22(12): p. 4062-72.

37. You, M., D.H. Yu, and G.S. Feng, Shp-2 tyrosine phosphatase functions as a negative regulator of the interferon-stimulated Jak/STAT pathway. Molecular and cellular biology, 1999. 19(3): p. 2416-2424.

38. You, M., et al., Modulation of the Nuclear Factor $\kappa b$ Pathway by Shp-2 Tyrosine Phosphatase in Mediating the Induction of Interleukin (II)-6 by IL-1 or Tumor Necrosis Factor. The Journal of Experimental Medicine, 2001. 193(1): p. 101-110.

39. Takahashi, A., et al., SHP2 Tyrosine Phosphatase Converts Parafibromin/Cdc73 from a Tumor Suppressor to an Oncogenic Driver. Molecular Cell, 2011. 43(1): p. 45-56.

40. Burks, J. and Y.M. Agazie, Modulation of alpha-catenin Tyr phosphorylation by SHP2 positively effects cell transformation induced by the constitutively active FGFR3. 
Oncogene, (2006 Jun 12): p. 2006 Nov 16;25(54):7166-79.

41. Ren, Y., et al., Critical Role of Shp2 in Tumor Growth Involving Regulation of c-Myc. Genes \& Cancer, 2010. 1(10): p. 994-1007.

42. Chan, G., D. Kalaitzidis, and B. Neel, The tyrosine phosphatase Shp2 in cancer. Cancer and Metastasis Reviews, 2008. 27(2): p. 179-192.

43. Tartaglia, M., et al., Somatic mutations in PTPN11 in juvenile myelomonocytic leukemia, myelodysplastic syndromes and acute myeloid leukemia. Nat Genet, 2003. 34(2): p. 14850.

44. Bentires-Alj, M., et al., Activating Mutations of the Noonan Syndrome-Associated SHP2/PTPN11 Gene in Human Solid Tumors and Adult Acute Myelogenous Leukemia. Cancer Research, 2004. 64(24): p. 8816-8820.

45. Hatakeyama, M., Oncogenic mechanisms of the Helicobacter pylori CagA protein. Nat Rev Cancer, 2004. 4(9): p. 688-94.

46. Bentires-Alj, M., et al., A role for the scaffolding adapter GAB2 in breast cancer. Nat Med, 2006. 12(1): p. 114-121.

47. Zhou, X., et al., SHP2 is up-regulated in breast cancer cells and in infiltrating ductal carcinoma of the breast, implying its involvement in breast oncogenesis. Histopathology, (2008 Jul 15): p. 2008 Oct;53(4):389-402.

48. Zhou, X.D. and Y.M. Agazie, Inhibition of SHP2 leads to mesenchymal to epithelial transition in breast cancer cells. Cell Death Differ, 2008. 15(6): p. 988-996.

49. Aceto, N., et al., Tyrosine phosphatase SHP2 promotes breast cancer progression and maintains tumor-initiating cells via activation of key transcription factors and a positive feedback signaling loop. Nat Med, 2012. 18(4): p. 529-537. 
50. Zhou, X., et al., SHP2 is up-regulated in breast cancer cells and in infiltrating ductal carcinoma of the breast, implying its involvement in breast oncogenesis. Histopathology, 2008. 53(4): p. 389-402.

51. Ivanov, A.V., et al., PHD Domain-Mediated E3 Ligase Activity Directs Intramolecular Sumoylation of an Adjacent Bromodomain Required for Gene Silencing. Molecular Cell, 2007. 28(5): p. 823-837.

52. Diermeier-Daucher, S., et al., Cell type specific applicability of 5-ethynyl-2'-deoxyuridine (EdU) for dynamic proliferation assessment in flow cytometry. Cytometry Part A, 2009. 75A(6): p. 535-546.

53. Dontu, G., et al., In vitro propagation and transcriptional profiling of human mammary stem/progenitor cells. Genes Dev, 2003. 17(10): p. 1253-70.

54. Burness, M.L., T.A. Grushko, and O.I. Olopade, Epidermal growth factor receptor in triple-negative and basal-like breast cancer: promising clinical target or only a marker? Cancer J. 16(1): p. 23-32.

55. Hollestelle, A., et al., Distinct gene mutation profiles among luminal-type and basal-type breast cancer cell lines. Breast Cancer Res Treat. 121(1): p. 53-64.

56. Neve, R.M., et al., A collection of breast cancer cell lines for the study of functionally distinct cancer subtypes. Cancer Cell, 2006. 10(6): p. 515-27.

57. Neve Rm Fau - Chin, K., et al., A collection of breast cancer cell lines for the study of functionally distinct cancer subtypes. (1535-6108 (Print)).

58. Agelopoulos, K., et al., Selective regain of egfr gene copies in CD44+/CD24-/low breast cancer cellular model MDA-MB-468. BMC Cancer, 2010. 10: p. 78.

59. Hirsch, D.S., Y. Shen, and W.J. Wu, Growth and motility inhibition of breast cancer cells 
by epidermal growth factor receptor degradation is correlated with inactivation of Cdc42. Cancer Res, 2006. 66(7): p. 3523-30.

60. Yu, D.-H., et al., Protein-tyrosine Phosphatase Shp-2 Regulates Cell Spreading, Migration, and Focal Adhesion. Journal of Biological Chemistry, 1998. 273(33): p. 21125-21131.

61. Oh, E.S., et al., Regulation of early events in integrin signaling by protein tyrosine phosphatase SHP-2. Mol Cell Biol, 1999. 19(4): p. 3205-15.

62. Reddy, K.B., et al., Mitogen-activated protein kinase (MAPK) regulates the expression of progelatinase B (MMP-9) in breast epithelial cells. Int J Cancer, 1999. 82(2): p. 268-73.

63. Ruhul Amin, A.R., et al., A role for SHPS-1/SIRPalpha in Concanavalin A-dependent production of MMP-9. Genes Cells, 2007. 12(9): p. 1023-33.

64. Ruhul Amin, A.R., et al., SH2 domain containing protein tyrosine phosphatase 2 regulates concanavalin A-dependent secretion and activation of matrix metalloproteinase 2 via the extracellular signal-regulated kinase and p38 pathways. Cancer Res, 2003. 63(19): p. 6334-9.

65. Wang, F.M., et al., SHP-2 promoting migration and metastasis of MCF-7 with loss of Ecadherin, dephosphorylation of FAK and secretion of MMP-9 induced by IL-1beta in vivo and in vitro. Breast Cancer Res Treat, 2005. 89(1): p. 5-14.

66. Klopp, A.H., et al., Mesenchymal Stem Cells Promote Mammosphere Formation and Decrease E-Cadherin in Normal and Malignant Breast Cells. PLoS One, 2010. 5(8): p. e12180.

67. Al-Hajj, M., et al., Prospective identification of tumorigenic breast cancer cells. Proc Natl Acad Sci U S A, (2003 Mar 10): p. 2003 Apr 1;100(7):3983-8. 
68. Grimshaw, M.J., et al., Mammosphere culture of metastatic breast cancer cells enriches for tumorigenic breast cancer cells. Breast Cancer Res, (2008 Jun 9): p. 2008;10(3):R52.

69. Hochgrafe, F., et al., Tyrosine phosphorylation profiling reveals the signaling network characteristics of Basal breast cancer cells. Cancer Res, (2010 Sep 21): p. 2010 Nov 15;70(22):9391-401.

70. Geyer, F.C., et al., beta-Catenin pathway activation in breast cancer is associated with triple-negative phenotype but not with CTNNB1 mutation. Mod Pathol, (2010 Nov 12): p. 2011 Feb;24(2):209-31.

71. von Lintig, F.C., et al., Ras activation in human breast cancer. Breast Cancer Research and Treatment, 2000. 62(1): p. 51-62.

72. Scherr, M., et al., Enhanced sensitivity to inhibition of SHP2, STAT5, and Gab2 expression in chronic myeloid leukemia (CML). Blood, (2005 Nov 8): p. 2006 Apr 15;107(8):3279-87.

73. Milarski, K.L. and A.R. Saltiel, Expression of catalytically inactive Syp phosphatase in $3 T 3$ cells blocks stimulation of mitogen-activated protein kinase by insulin. Journal of Biological Chemistry, 1994. 269(33): p. 21239-21243.

74. Shi, Z.Q., W. Lu, and G.S. Feng, The Shp-2 tyrosine phosphatase has opposite effects in mediating the activation of extracellular signal-regulated and c-Jun NH2-terminal mitogen-activated protein kinases. J Biol Chem, 1998. 273(9): p. 4904-8.

75. Agazie, Y.M., et al., The phosphotyrosine phosphatase SHP2 is a critical mediator of transformation induced by the oncogenic fibroblast growth factor receptor 3. Oncogene, 0000. 22(44): p. 6909-6918.

76. Hakak, Y., Y.S. Hsu, and G.S. Martin, Shp-2 mediates v-Src-induced morphological 
changes and activation of the anti-apoptotic protein kinase Akt. Oncogene, 2000. 19(28): p. 3164-71.

77. Rodriguez, L.G., X. Wu, and J.L. Guan, Wound-healing assay. Methods Mol Biol, 2005. 294: p. 23-9.

78. Yang, X., U. Dutta, and L.M. Shaw, SHP2 mediates the localized activation of Fyn downstream of the alpha6beta4 integrin to promote carcinoma invasion. Mol Cell Biol, (2010 Sep 20): p. 2010 Nov;30(22):5306-17.

79. Kondapaka, S.B., R. Fridman, and K.B. Reddy, Epidermal growth factor and amphiregulin up-regulate matrix metalloproteinase-9 (MMP-9) in human breast cancer cells. Int J Cancer, 1997. 70(6): p. 722-6.

80. King, T.D., M.J. Suto, and Y. Li, The Wnt/beta-catenin signaling pathway: a potential therapeutic target in the treatment of triple negative breast cancer. J Cell Biochem, (10): p. 2012 Jan;113(1):13-8.

81. He, T.C., et al., Identification of c-MYC as a target of the APC pathway. Science, 1998. 281(5382): p. 1509-12.

82. Khramtsov, A.I., et al., Wnt/beta-catenin pathway activation is enriched in basal-like breast cancers and predicts poor outcome. Am J Pathol, (2010 Apr 15): p. 2010 Jun;176(6):2911-20. 